\title{
Asymptotic and Finite Sample Properties of the QMLE for the Log-ACD Model: Application to Australian Stocks*
}

\author{
David Allen \\ School of Accounting, Finance and Economics \\ Edith Cowan University
}

Felix Chan

School of Economics and Finance

Curtin University of Technology

Michael McAleer

School of Economics and Commerce

University of Western Australia

\section{Shelton Peiris}

Department of Mathematics and Statistics

University of Sydney

Revised: May 2007

* The authors are most grateful for the insightful comments and suggestions of Jiti Gao and two referees, the financial support of the Australian Research Council, and the data provided by our industry research partner, Securities Industry Research Centre of the Asia Pacific (SIRCA).

Corresponding author:

David E. Allen

School of Accounting, Finance and Economics

Faculty of Business and Law

Edith Cowan University

Joondalup, WA 6027, Australia

Email: d.allen@ecu.edu.au 


\begin{abstract}
This paper examines the finite sample properties of the Quasi-Maximum Likelihood Estimator (QMLE) of the Logarithmic Autoregressive Conditional Duration (Log-ACD) model. Proofs of consistency and asymptotic normality of the QMLE for the log-ACD model with a log-normal density are presented. This is an important issue as the Log-ACD is used widely for testing various market microstructure models and effects. Knowledge of the distribution of the QMLE is crucial for purposes of drawing valid inferences and diagnostic checking. The theoretical results developed in the paper are evaluated using Monte Carlo experiments. The experimental results also provide insight into the finite sample properties of the Log-ACD model under different distributional assumptions. Finally, this paper presents two extensions to the Log-ACD model to accommodate asymmetric effects. The practical usefulness of the new models is evaluated using empirical data from Australian stocks.
\end{abstract}

Keywords: Conditional Duration, Asymmetry, Autoregressive Conditional Duration, Logarithmic Autoregressive Conditional Duration, Monte Carlo Simulations. 


\section{Introduction}

An accurate description of the dynamics of duration between stock price changes has important implications and applications for the analysis of financial markets. Engle and Russell (1997) proposed the Autoregressive Conditional Duration (ACD) model, which assumes that the duration between price changes follows a process similar to that of Bollerslev's (1986) Generalised Autoregressive Conditional Heteroscedasticity (GARCH) model. Both models are based on dynamic time series processes in the underlying variables. Due to the structural similarity between the GARCH and ACD models, Engle and Russell (1997) provided a proof of consistency and asymptotic normality for the QMLE of the ACD model following the approach of Lee and Hansen (1994), arguing that the theoretical results could be applied directly to the ACD model. Based on this result, researchers have subsequently proposed numerous extensions to the ACD model in a similar manner to the extensions of the GARCH model (for a discussion of the structural and statistical properties of a variety of univariate and multivariate conditional volatility models, see McAleer (2005)). These extensions include Bauwens and Giot's (2000) Logarithmic ACD (Log-ACD) model, Dufour and Engle's (2000) Box-Cox ACD (BCACD) model and Exponential ACD (EXPACD) model, Zhang, Russell and Tsay's (2001) Threshold ACD (TACD) model, and Hujer, Kokot and Vuletic's (2003) Markov Switching ACD (MSACD) model.

This paper is concerned with the asymptotic and finite sample properties of the Quasi-Maximum Likelihood Estimator (QMLE) for the Log-ACD model. The motivation is two-fold. First, Engle and Russell (1997) derived the asymptotic properties of the ACD model based on the results of Lee and Hansen (1994) for the GARCH model. However, such asymptotic properties are not yet available for the volatility counterpart of the Log-ACD model, namely Nelson's (1991) Exponential GARCH (EGARCH) model. Therefore, the distribution of the QMLE for Log-ACD is still unknown, which is particularly important as the ACD model is often used for testing hypotheses about the market microstructure. Thus, the distribution of QMLE is crucial for purposes of drawing valid inferences and diagnostic checking. Second, in the GARCH literature the standardised residuals are often assumed to be normally distributed. The QMLE based on the normal density has been proved to be consistent and asymptotically normal under fairly general conditions (see Ling and McAleer (2003)). However, the assumption of normality cannot be applied to ACD (or Log-ACD) models as the standardised residuals of these models are required to be positive. The Weibull, exponential, generalised gamma and log-normal are four of the most widely used probability density functions (pdf). A natural question is the nature of the statistical 
properties of QMLE for the Log-ACD model based on a variety of alternative probability distributions.

This paper established proofs of consistency and asymptotic normality of the QMLE for the LogACD model with log-normal density. The theoretical results developed in the paper are evaluated using Monte Carlo experiments. The experimental results also provide insight into the finite sample properties of the Log-ACD model under different distributional assumptions.

Moreover, the relationship between the Log-ACD and the Autoregressive Moving Average (ARMA) model will also be discussed in detail. As the structural and statistical properties of the ARMA process are well established, the properties for the ARMA model will also apply to the Log-ACD model. Moreover, the statistical properties of the ARMA model with exogenous variables (ARMAX) will also apply to the Log-ACD model with exogenous variables. This is particularly important as ACD models with exogenous variables are often used for purposes of testing hypotheses about market microstructures. Therefore, these properties are crucial for ensuring valid inferences and diagnostic checking.

The second part of the paper proposes two alternative methods for accommodating asymmetric effects. The Log-ACD model assumes that the duration between price movements is affected only by the previous duration but not by the direction of the price change. However, since the market frequently has a different attitude to price rises as compared with price falls of equal magnitude, it is important to examine how the direction of the price movement affects the future duration.

Although many alternative asymmetric ACD models have been proposed in the literature, including Zhang, Russell and Tsay's (2001) Threshold ACD (TACD) model, and Hujer, Kokot and Vuletic's (2003) Markov Switching ACD (MSACD) model, these models often lack structural and/or statistical properties and can be difficult to estimate. Moreover, using these models for purposes of testing hypotheses about market microstructure is not always straightforward. However, the methods proposed in this paper are simple and straightforward to implement in practice. Moreover, the structural and statistical properties of the Threshold Autoregressive (TAR) model and ARMAX model can be applied directly to the two new asymmetric models that are proposed in this paper. 
The empirical performance of the models will be examined using tick-by-tick data for eight Australia shares that are traded on the Australia Stock Exchange (ASX).

The remainder of the paper is organised as follows. Section 2 discusses the Log-ACD model and the distributions that are most frequently used for obtaining the QMLE. A novel method of estimation is also proposed. The statistical properties of QMLE for the Log-ACD model with lognormal density will be analysed in detail. Section 3 provides the Monte Carlo experiments and numerical results to examine the finite sample properties. Section 4 presents two new models for accommodating asymmetric effects. The data are discussed in Section 5. Empirical examples and estimates are given in Section 6. Finally, Section 7 contains some concluding comments.

\section{Model Specifications and Theoretical Results}

\subsection{ACD Model}

Engle and Russell (1994) proposed the Autoregressive Conditional Duration (ACD) model as follows:

$$
\begin{aligned}
& x_{i}=\psi_{i} \varepsilon_{i}, \quad \varepsilon_{i} \sim \text { iid } \\
& \psi_{i}=\omega+{ }_{j=1}^{p} \alpha_{j} x_{i-j}+{ }_{j=1}^{q} \beta_{j} \psi_{i-j},
\end{aligned}
$$

where $x_{i}$ is the duration and $\varepsilon_{i}$ is the independently and identically distributed (iid) innovation. The connection between the structures of the ACD and GARCH models is obvious. Considering

$y_{i}=\sqrt{x_{i}}$ (which always holds as duration is always positive), then $y_{i}$ essentially follows a $\operatorname{GARCH}(p, q)$ process.

As $x_{i}$ is positive for all $i$, it is natural to assume that $\psi_{i}$ and $\varepsilon_{i}$ are both positive. Mathematically, $\varepsilon_{i}$ can follow any distribution $F(x)$ with probability $P(x<0)=0$. A sufficient condition to ensure the positivity of $\psi_{i}$ is $\omega>0, \alpha_{i}>0 \forall i=1, \ldots, p$ and $\beta_{i} \geq 0 \forall i=1, \ldots, q$. This condition is identical to that of the GARCH model for ensuring that the conditional variance is positive. 
However, as this sufficient condition may be too restrictive in some cases, Bauwens and Giot (2000) resolved the issue by proposing the Logarithmic ACD (Log-ACD) model, as follows:

$$
\begin{gathered}
x_{i}=\exp \left(\varphi_{i}\right) \varepsilon_{i} \\
\varphi_{i}=\omega+{ }_{j=1}^{p} \alpha_{j} \log x_{i-j}+{ }_{j=1}^{q} \beta_{j} \varphi_{i-j} .
\end{gathered}
$$

Note that $E\left(\varepsilon_{i}\right)=v>0$, so that

$$
E\left(x_{i} \mid I_{i-1}\right)=v \exp \left(\varphi_{i}\right)
$$

where $I_{i}$ is the information set available up to the $i^{\text {th }}$ price change. Let $\exp \left(\phi_{i}\right)=v \exp \left(\varphi_{i}\right)$, with

$$
\phi_{i}=\varpi+{ }_{j=1}^{p} \alpha_{j} \log x_{i-j}+{ }_{j=1}^{q} \beta_{j} \phi_{i-j},
$$

where $\varpi=\omega+\log v$. Then $E\left(x_{i} \mid I_{i-1}\right)=\exp \left(\phi_{i}\right)$, and equation (2) can be rewritten as

$$
\begin{gathered}
x_{i}=\exp \left(\phi_{i}\right) \eta_{i} \\
\phi_{i}=\varpi+{ }_{j=1}^{p} \alpha_{j} \log x_{i-j}+{ }_{j=1}^{q} \beta_{j} \phi_{i-j},
\end{gathered}
$$

where $\eta_{i}=\frac{\varepsilon_{i}}{v}$. Equation (3) is more convenient for purposes of obtaining the QMLE as $E\left(\eta_{i}\right)=1$, and hence avoids potential identification problems.

The parameters in model (3) can be estimated by the Maximum Likelihood method. Let $l(\theta)$ be the log-likelihood function with parameter vector $\lambda=\left(\theta^{\prime}, s^{\prime}\right)^{\prime}$, so that

$$
l(\lambda)=\sum_{i=1}^{T} \log f\left(x_{i}, \lambda\right)
$$


where $\theta=\left(\omega, \alpha_{1}, \ldots, \alpha_{p}, \beta_{1}, \ldots, \beta_{q}\right)^{\prime}$ and $s=\left(s_{1}, \ldots, s_{k}\right)^{\prime}$ denote the additional parameters required by the density function, $f\left(x_{i}, \lambda\right)$. Then the Maximum Likelihood Estimator (MLE), $\hat{\lambda}$, of $\lambda$, is given by

$$
\hat{\lambda}=\underset{\lambda \in \Lambda}{\arg \max } l(\lambda)
$$

However, the functional form of the likelihood function depends on the distribution of $\eta_{i}$. Mathematically, $\eta_{i}$ can follow any distribution function, $F(x)$, such that $P(x<0)=0$. Some of the most popular choices for the distribution of $\eta_{i}$, and their density functions, are as follows:

1. Lognormal distribution:

$$
f_{1}(x)=\frac{1}{x s \sqrt{2 \pi}} \exp \left(-\frac{1}{2}\left(\frac{\log (x)-m}{s}\right)^{2}\right)
$$

2. Weibull distribution:

$$
f_{2}(x)=\frac{g}{s}\left(\frac{x-m}{s}\right)^{g-1} \exp \left(-\left(\frac{x-m}{s}\right)^{g}\right)
$$

3. Generalised Gamma distribution:

$$
f_{3}(x)=\frac{g}{\Gamma(k) s}\left(\frac{x}{s}\right)^{k g-1} \exp \left(-\left(\frac{x}{s}\right)^{g}\right)
$$

4. Exponential distribution:

$$
f_{4}(x)=s \exp (-s x)
$$

where $m$ denotes the location parameter, $s$ denotes the scale parameter, $g$ and $k$ denote the additional scale parameters, and $\Gamma(k)$ is the gamma function, such that 


$$
\Gamma(k)={ }_{0}^{\infty} s^{k-1} \exp (-s) d s .
$$

The log-likelihood function in each case is given by equation (4), with $f\left(x_{i}, \lambda\right)$ replaced by the appropriate density function.

In practice, the true distribution of $\eta_{i}$ is seldom known, such that $\hat{\lambda}$, as defined in equation (5), will be the Quasi-MLE (QMLE) rather than the MLE. Engle and Russell (1997) suggested using the Bollerslev-Wooldridge (1992) robust covariance matrix, $H(\hat{\lambda})$, instead of the asymptotic covariance matrix, to obtain the variance for $\hat{\lambda}$, where

$$
H(\hat{\lambda})=\left.E\left(\frac{\partial^{2} l}{\partial \lambda \partial \lambda^{\prime}}\right)^{-1}\left(\frac{\partial l}{\partial \lambda}\right)\left(\frac{\partial l}{\partial \lambda}\right)^{\prime}\left(\frac{\partial^{2} l}{\partial \lambda \partial \lambda^{\prime}}\right)^{-1^{\prime}}\right|_{\lambda=\hat{\lambda}}
$$

Although several papers have attempted to derive the moment conditions for the ACD and LogACD models (see, for example, Bauwens, Galli and Giot (2003)), the statistical properties of the QMLE for the Log-ACD model are still unknown (see Ghysels and Jasiak (1997) and Feng, Jiang and Song (2004)).

Another interesting feature of the Log-ACD model is the possibility of linearising the process. Note that

$$
\begin{aligned}
& x_{i}=\exp \left(\phi_{i}\right) \eta_{i} \\
& \log x_{i}=\phi_{i}+\log \eta_{i} \\
& \log x_{i}=\phi_{i}+\mu_{i}
\end{aligned}
$$

where $\mu_{i}=\log \eta_{i}$. Under the assumption that $\eta_{i}$ follows a log-normal distribution, this implies that $\mu_{i}$ follows a normal distribution. Therefore, the log-likelihood function for (11) can be written as

$$
l(\theta)=-\frac{1}{2}_{i=1}^{T} \log s^{2}+\frac{\log x_{i}-\phi_{i}}{s}
$$


Equation (11) models the logarithm of duration rather than duration itself. The advantage of this approach is that $\log x_{i}$ can now be rewritten as an $\operatorname{ARMA}(\mathrm{r}, \mathrm{r})$ process, where $r=\max (p, q)$, as shown in the following proposition:

Proposition 1: If the random variable, $x_{i}$, follows the stochastic process, as defined in equation (3), then $\log x_{i}$ can be represented as a $\operatorname{ARMA}(\mathrm{r}, \mathrm{r})$ process, where $r=\max (p, q)$, that is

$$
\log x_{i}=\tilde{w}+\sum_{j=1}^{r} \delta_{j} \log x_{i-j}+\sum_{j=1}^{r} \theta_{j} \xi_{i-j}+\xi_{i}
$$

where $\xi_{i} \sim \operatorname{iid}\left(0, \sigma_{\xi}^{2}\right)$ and $\tilde{w}=w+\sum_{j=1}^{r} \theta_{j} E\left(\mu_{i}\right)+E\left(\mu_{i}\right)$.

Proof: See Appendix.

Remark 1: It is straightforward to show that the conditional likelihood for equation (13) is equivalent to that of equation (12), so that the existing structural and statistical properties of the $\operatorname{ARMA}(p, q)$ model can be applied directly to the model given in equation (11). The statistical properties of the QMLE under a log-normal density will be presented in the next sub-section. The finite sample performance of this estimation method will be analysed in Section 3.

\subsection{Theoretical Results}

This section establishes the statistical properties, namely consistency and asymptotic normality of the QMLE with a log-normal density for the Log-ACD model, as defined in equation (3). The moment structure of the log-ACD model has been established in Bauwens, Galli and Giot (2003).

Consider the Log-ACD model, as defined in equation (3). The associated log-likelihood function with a log-normal density is defined as

$$
\begin{aligned}
& l(\lambda)=\sum_{i=1}^{T} l_{i}(\lambda) \\
& l_{i}(\lambda)=\log f\left(x_{i}, \lambda\right)=-\frac{1}{2} \log 2 \pi-\frac{1}{2} \log s^{2}-\log x_{i}-\frac{1}{2} \frac{\left(\log x_{i}-\phi_{i}\right)^{2}}{s^{2}}
\end{aligned}
$$


where $\alpha=\left(\alpha_{1}, \ldots, \alpha_{p}\right)^{\prime}, \beta=\left(\beta_{1}, \ldots, \beta_{q}\right)^{\prime}, \theta=\left(\omega, \alpha^{\prime}, \beta^{\prime}\right)^{\prime}, \lambda=\left(s^{2}, \theta^{\prime}\right)^{\prime}$, and $\alpha_{0}, \beta_{0}, \theta_{0}, \lambda_{0}$ denotes the true parameters of $\alpha, \beta, \theta, \lambda$, respectively.

The theoretical results are derived based under the following assumptions:

1. $\Lambda$ is an open subset of the Euclidean space, $R^{p+q+1}$, such that $\lambda_{0} \in \Lambda$.

2. $x_{i}$ is stationary and ergodic.

3. $\alpha(L)$ and $\beta(L)$ are left co-prime, where $\alpha(L)=\sum_{i=1}^{p} \alpha_{i} L^{i}$ and $\beta(L)=\sum_{i=1}^{q} \beta_{i} L^{i}$. Moreover, $\sum_{j=1}^{p} \alpha_{0 j}+\sum_{j=1}^{q} \beta_{0 j}<1$

4. $E\left(\log \eta_{i}\right)=0 \quad E\left[\left(\log \eta_{i}\right)^{2}\right]=s_{0}^{2} \quad \forall i=1, \ldots, T$.

Assumption 2 can be replaced by any conditions that ensure the stationarity and ergodicity of the duration process. The conditions of the existence of moments can be found in Bauwens, Galli and Giot (2003). Assumption 3 ensures the invertibility of the process and identification of the parameters. Moreover, Assumption 3 is likely to be a sufficient condition for Assumption 2. If this is the case, then Assumption 2 can be omitted. Assumption 4 is needed to ensure the existence of the first two moments of $\log x_{i}$, which is required for the log-normal density.

\section{Proposition 2:}

Under Assumptions (1)-(4), the Quasi-Maximum Likelihood Estimator (QMLE) in equation (14) for the log-ACD model, as defined in equation (3), is consistent, that is, $\hat{\lambda} \stackrel{p}{\rightarrow} \lambda_{0}$.

Proof: See Appendix.

\section{Proposition 3:}

Under Assumptions (1)-(4), the Quasi-Maximum Likelihood Estimate (QMLE) in equation (14) for the log-ACD model, as defined in equation (3), is asymptotically normal, $\sqrt{T}\left(\hat{\lambda}-\lambda_{0}\right) \stackrel{d}{\rightarrow} N\left(0, A\left(\lambda_{0}\right)^{-1} B\left(\lambda_{0}\right) A\left(\lambda_{0}\right)^{-1}\right)$, where $A\left(\lambda_{0}\right)=\left.\lim _{T \rightarrow \infty} T^{-1} E\left(\frac{\partial^{2} l}{\partial \lambda \partial \lambda^{\prime}}\right)\right|_{\lambda=\lambda_{0}}$ and $B\left(\lambda_{0}\right)=\left.\lim _{T \rightarrow \infty} T^{-1} E\left(\frac{\partial l}{\partial \lambda} \frac{\partial l}{\partial \lambda^{\prime}}\right)\right|_{\lambda=\lambda_{0}}$

Proof: See Appendix. 
Remark 2: The results in Propositions 2 and 3 apply explicitly to the Log-ACD model, as defined in equation (3), where the standardised residual, $\eta_{i}$, has a unit mean. It is unclear whether these results hold for models, as defined in equation (2), where the standardised residuals, $\varepsilon_{i}$, may have a mean that is different from unity. This should not pose a serious problem in practice as estimation is typically conducted for a Log-ACD model, as specified in equation (3), rather than the alternative specification, as defined in equation (2).

\section{Finite Sample Properties}

This section provides Monte Carlo evidence for the finite sample properties of the MLE and the QMLE, as defined in equation (5). The Data Generating Process (DGP) for each of the realisations is given by:

$$
\begin{aligned}
x_{i} & =\exp \left(\phi_{i}\right) \eta_{i} \\
\phi_{i} & =0.01+0.2 \log x_{i}+0.7 \phi_{i-1} .
\end{aligned}
$$

The steps for the Monte Carlo analysis in this section are as follows:

1. For each of the distributions as defined in equations (6)-(9), the DGP defined above will be used to generate realisations with sample sizes of 500, 1000 and 3000.

2. The parameters of the Log-ACD models will be estimated from the realisations generated in step 1 above by maximising the log-likelihood functions, as defined in equation (5), based on the distributions defined in equations (6)-(9) and the log-likelihood function defined in equation (4).

3. Repeat Steps 1 to 2 above 3000 times, so that there are 3000 replications.

The first set of results given in Tables $2 \mathrm{a}-2 \mathrm{c}$ provide an analysis of the properties of the QMLE as applied to the Log-ACD model, based on the Log-normal probability distributions. [Similar tables of results are available upon written request for the Weibull, exponential and generalised gamma distributions, all of which produce the required positive standardised residuals, but these are not provided for space considerations.] The results of the Monte Carlo experiments in Tables $2 \mathrm{a}-2 \mathrm{c}$ simulate the finite sample properties on the basis of sample sizes of 500, 1000 and 3000 , each with 3000 simulations. 
Overall, both MLE and QMLE are close to their true values, even in relatively small samples. It is interesting to note that the (Q)MLE based on the log-normal density, as defined in equation (6), is identical to those obtained by maximising equation (12). This should not be surprising as equation (12) is a monotonic transformation of the likelihood function based on the log-normal density, as defined in equation (6). Although the transformation does not affect the estimates, it does affect the standard deviation of the estimates, as can be seen in Tables $2 \mathrm{a}-2 \mathrm{c}$, as well as for the other three distributions that are not shown here. The (Q)MLE produce seemingly unbiased estimates of the parameters. Regardless of the true underlying distribution, the (Q)MLE by assuming the log-normal, Weibull and normal densities seem to be robust and asymptotically normal, which is supported by the skewness and kurtosis of the t-ratios for the estimates. As the sample size increases, the skewness and kurtosis of the (Q)MLE under the log-normal, Weibull and normal densities tend towards 0 and 3, respectively. In addition, as the sample size increases, the Jarque-Bera Lagrange multiplier statistics also generally lead to non-rejection of the null hypothesis of normality. Moreover, the convergence rates seem to be faster for MLE than for QMLE in these cases, which is not surprising as MLE should be more efficient than QMLE.

Although not shown here, the finite sample properties of the QMLE under the assumption of the generalised gamma and exponential distributions are less than desirable in some cases. The problem with the generalised gamma distribution is due partly to the difficulties in obtaining robust and accurate numerical derivatives of the likelihood functions for purposes of maximisation. This could be improved by specifying the analytical derivatives of the likelihood function in the optimisation routine. The problem with the exponential distribution is more basic. In many cases, the exponential distribution simply does not have the flexibility to approximate the true underlying distribution, which leads to poor finite sample properties, even though the QMLE with exponential density may be asymptotically normal.

These Monte Carlo results suggest that the choice of density to determine the likelihood function is important. The density should be sufficiently flexible to provide a good approximation to a wide range of distributions, but also sufficiently accurate so that it does not induce unnecessary numerical difficulties.

\section{Asymmetric Log-ACD Model}

The Log-ACD model, as defined in equation (3), assumes that the conditional duration is affected by the previous duration but not by the direction of the previous price change. In other words, the 
model assumes that a positive price change has the same impact on the duration for the next price movement as does a negative price change of similar magnitude. It is important to note that the movements in both bid and ask prices contain important information regarding the overall performance of the stock. Thus, it would not seem reasonable to assume that the frequency of price changes is unaffected by the direction of previous price changes.

There are numerous models that extend the basic ACD model in a variety of ways. This paper proposes two straightforward methods of accommodating asymmetry into the basic ACD model. Bauwens and Giot (2006) refer to 'first generation ACD' models, which begin with the linear ACD model of Engle and Russell (1998) and the logarithmic ACD (Log-ACD) model of Bauwens and Giot (2000), together with further extensions into augmented ACD classes by Fernandes and Grammig (2006), and Hautsch's (2006) semi-parametric model. As mentioned previously, all these models have GARCH counterparts. The 'second generation' ACD models consist of regime-switching ACD models and mixture models. Such mixture can involve both the error distribution and the dynamic component. Zhang et al. (2001) develop a threshold ACD model (TACD), while Meitz and Terasvirta (2006) develop a class of smooth transition ACD models (STACD), which generalise the linear and logarithmic models in a particular way.

The two extensions presented here belong to the first generation of models, and the models are similar in spirit to those given in Bauwens and Giot (2003). These extensions model the direction of the price change between consecutive trades by means of a competing risks model; in which the direction of the price change is triggered by a Bernoulli process, thereby leading to a form of asymmetric ACD model. The basic linear ACD models only capture the duration between market events and do not include information given by the price process, which is of great importance in the context of market microstructure issues and the process of information impounding. The combination of information given by the price process and the duration between market events is an important extension. This was first addressed by Engle (2000), who suggested an ACDGARCH model. The durations were captured by a marginal ACD model, and the volatility of returns was modelled by a GARCH process, conditionally on the duration. Russell and Engle (2005) combine an ACD model to capture durations and a generalised linear model on conditional probabilities of the price process in their autoregressive conditional multinomial (ACM) model.

For this reason, two asymmetric Log-ACD models are proposed here to capture the asymmetric properties of the conditional duration. Model 1 uses an indicator function to capture asymmetric 
effects in a similar manner to that of the Glosten, Jagannathan and Runkle (1992) GJR model for capturing asymmetric effects in models of conditional volatility. Model 2 accommodates asymmetric effects by using dummy variables. Although both models are intended to capture asymmetric effects, the interpretation of the two models is quite different. Thus, they should be viewed as complementary rather than competing models. In addition, it is important to note that Models 1 and 2 can be rewritten as Threshold Autoregressive Moving Average (TARMA) and ARMAX models, respectively. Hence, the structural and statistical properties of the proposed models can be easily established using existing theoretical results, which will facilitate the testing of various hypotheses regarding the market microstructure.

\subsection{Model 1: Asymmetric Log-ACD using an indicator function (ALACDI)}

The first approach to accommodate any asymmetric effects is similar to that of the Glosten, Jagannathan and Runkle (1992) GJR model for capturing asymmetric effects in conditional volatility models. Let $D_{i}$ be an indicator function, such that

$$
D_{i}= \begin{cases}0, & \Delta p_{i} \geq 0 \\ 1, & \Delta p_{i}<0\end{cases}
$$

where $\Delta p_{i}=p_{i}-p_{i-1}$ and $p_{i}$ denotes the price level at the $i^{t h}$ significant price change. The Asymmetric Log-ACD model can be defined as

$$
\phi_{i}=\varpi+\sum_{j=1}^{r}\left(\alpha_{j}+\gamma_{j} D_{i-j}\right) \log x_{i-j}+\sum_{j=1}^{s} \beta_{j} \phi_{i-j}
$$

Note that, if $\gamma_{j}=0, \forall j$, then equation (16) reduces to the Log-ACD model, as defined in equation (3). Considering the special case, $r=s=1$, the short run persistence of the conditional duration is $\alpha_{1}$ if the previous price change is positive, while the short run persistence is $\alpha_{1}+\gamma_{1}$ if the previous price change is negative.

Using a similar argument as presented in the previous section, equation (16) can be rewritten as a Threshold Autoregressive Moving Average (TARMA) model. However, unlike the standard TAR model in the non-linear time series literature, where the threshold value is a parameter to be estimated, the threshold value in this case is fixed at 0 . More importantly, the structural and statistical properties developed for the TAR model can then be applied directly to equation (16) 
(see Tong (1983), Chan and Tong (1986), and Hansen (2001) for further details regarding the structural and statistical properties of TAR models).

\subsection{Model 2: Asymmetric Log-ACD Model using Exogenous Variables (ALACDX)}

The second approach to accommodate asymmetric effects is to augment the original Log-ACD model by including some exogenous variables. In this case, the model can be defined as

$$
\phi_{i}=\varpi+\sum_{j=1}^{p} \alpha_{j} \log x_{i-j}+\sum_{j=1}^{q} \beta_{j} \phi_{i-j}+\sum_{j=1}^{r} \delta_{j} D_{i-j}+\sum_{j=1}^{s} \lambda_{j} X_{j i}
$$

where $D_{i}$ is an indicator function, as defined in equation (15), and $X_{j i}$ denotes the value of the $j^{\text {th }}$ exogenous variable at the $i^{\text {th }}$ price change.

In our subsequent empirical analysis, we adopt bid and ask volume as the exogenous variables. Blume, Easley and O'Hara (1994) investigate the informational role of volume traded and show that it is potentially useful for technical analysis. In their model, volume statistics provide information about information precision that cannot be deduced from price statistics alone. Volume may convey additional information to price but the link between information asymmetry and volume traded is not necessarily linear.

Kyle (1985) was one of the first to develop a model whereby a single trader, presumed to have a monopoly on information, places orders over time so as to maximize trading profit before the information becomes common knowledge. Barclay and Warner (1993) find that informed traders concentrate their orders on medium-sized trades. They examined the proportion of a stock's cumulative price change that occurs in each trade-size category using transactions data for a sample of New York Stock Exchange (NYSE) firms. The stealth trading hypothesis suggests that, if privately informed traders concentrate their trades in medium sizes, and if stock-price movements are due mainly to private information revealed through these investors' trades, then most of a stock's cumulative price change will occur on medium-size trades. Their findings supported the stealth trading hypothesis, which suggests there will not necessarily be a simple relationship between volume and price duration.

Volume at the bid and ask is a common way of viewing market depth. Does net buy and net sell volume of the same size convey the same amount of information? Karpoff (1988) advances an 
argument that short selling restrictions may prevent insiders from exploiting negative information in the stock market. This suggests that higher information content might be attached to buy orders as compared with sell orders. There is some evidence in support of this short selling hypothesis in Karpoff (1988), Madhavan/Smidt (1991), and Chan and Lakonishok (1993). This argument also provides further impetus in support of our asymmetric ACD model.

Note that it is straightforward to show, using similar arguments to those presented in the previous section, that equation (17) can be rewritten as an ARMAX model. Hence, the structural and statistical properties developed for the ARMAX model can be applied directly to equation (17) without modification.

As mentioned previously, the interpretations of the two models are quite different. Model 1 suggests positive and negative price movements have different effects on the short run persistence of conditional durations. However, Model 2 suggests that the unconditional expectation of duration is different for positive and negative price movements. Thus, these models accommodate two different asymmetric effects on the conditional duration. The empirical performance of the two models will be examined in the next section.

\section{Data}

The two asymmetric models were applied to eight shares listed on the Australian Stock Exchange (ASX) using tick-by-tick data for the period $1 / 7 / 2003$ to $1 / 10 / 2003$. The eight shares are Commonwealth Bank of Australia (CBA), BHP Billiton (BHP), QANTAS Airways (QAN), Coles-Myer Limited (CML), Telstra (TLS), Australia and New Zealand Bank (ANZ), Woolworths (WOW) and Woodside Petroleum (WPL). These eight companies cover a wide range of industries and service areas that include the mining, energy and retail industries, telecommunications and the banking sector.

Data were provided by our industry research partner, Securities Industry Research Centre of the Asia Pacific (SIRCA). SIRCA is a not-for-profit research consortium of 26 universities drawn from Australia and New Zealand, together with a number of industry partners, including the Australian Stock Exchange (ASX), the Sydney Futures Exchange (SFE), and Reuters. This research draws upon SIRCA's ASX intra-day data, which captures all the transactions occurring on the ASX via the Stock Exchange Automated Trading System (SEATS). The data possess a wealth of information, including the date and time (to the nearest hundredth of a second that the 
trade took place), price information, including details of the bid and ask prices, volumes, order flow (disclosed and undisclosed), value and volumes of trades, broker IDs, and order flags.

This paper applies the various Log-ACD models discussed above to eight Australian companies, representing five different industries in Australia. Australia and New Zealand Banking Group Limited (ANZ) and Commonwealth Bank of Australia (CBA) are selected to represent the banking industry of Australia. BHP Billiton Limited (BHP) and Woodside Petroleum Limited (WPL) are selected to represent the Mining and Energy Industry of Australia. Coles Myer Ltd (CML) and Woolworths Limited (WOW) are selected to represent the Retail Industry of Australia. Telstra Corporation Limited (TLS) and QANTAS Airways Limited (QAN) are selected to represent the Telecommunications and Transportation Industries for Australia, respectively. The summary statistics and their sample sizes are given in Table 1.

The calculation of duration follows Engle and Russell (1998), and the data are further filtered by the cubic spline method, as suggested in Engle and Russell (1998), to remove the time-of-day effects.

\section{Empirical Results}

Tables 3a-3d contain the parameter estimates of Models (3), (16) and (17) for ANZ. In order to save space, the tables for the remaining seven companies are not reported, but are available upon written request. For all companies, each model was estimated four times with different distributional assumptions, namely the log-normal, Weibull, exponential and normal distributions, as discussed in Section 2. The generalised gamma distribution is omitted due to its computational difficulties, as outlined in Section 3. Additional exogenous variables, namely the bid and ask volumes, are also included in the ALACDX model to examine the impact of traded volumes in the previous price change on the duration of the subsequent price change.

The Ljung-Box Q-statistics and the BDS statistics are also calculated using the standardised residuals for each case. The results support serial independence in the standard residuals, which support the consistency of the QMLE. However, the Kolmogorov-Smirnov test provides strong evidence to reject the null hypothesis of the assumed distribution in each case, which indicates that the underlying distribution is unlikely to be the correct distribution. However, the existence of some outliers and extreme observations may be the cause of these test outcomes, and would be an interesting area for further research. 


\subsection{Banking Industry}

As shown in Tables 3a-3d for ANZ, the $\alpha$ and $\beta$ estimates are positive and significant for ANZ, and also for CBA, for each of the four estimated models. These results suggest that past durations are helpful in predicting the duration before the next price change. However, there is no evidence to support asymmetric effects on duration from price changes as both the $\gamma$ and $\delta$ estimates are insignificant for both banks. Interestingly, both the $\lambda_{1}$ and $\lambda_{2}$ estimates are positive and significant in each case, indicating that the traded bid and ask volumes at the last price change have a positive impact on duration. In addition, the inclusion of the bid and ask volumes also has a negative news impact on the $\beta$ estimates, which suggests that the correct specification of the model is crucial for obtaining valid inferences and diagnostic checks. Moreover, the problem of omitted variables could have important implications for the interpretation of the various models. The long run persistence of past duration on future conditional duration would also appear to be substantially lower when the bid and ask volumes are included in the analysis. The estimates have different values for the two banks, and the differences are most pronounced in the asymmetric models that include bid and ask volumes.

\subsection{Mining and Energy Industry}

The estimates for BHP and WPL, which represent the mining and energy industry of Australia, are not presented here. However, as in the case of the banking industry, the $\alpha$ and $\beta$ estimates are positive and significant for both BHP and WPL, indicating that past durations contain important information about the future duration of price changes. Although there is no evidence for asymmetric effects on duration from price changes, traded bid and ask volumes appear to have significant and positive effects on the conditional duration as $\lambda_{1}$ and $\lambda_{2}$ are both positive and significant. Again, the inclusion of the bid and ask volumes has a negative impact on the $\beta$ estimates. Moreover, the long run persistence of past duration on future conditional duration would appear to be lower when the bid and ask volumes are included in the analysis.

\subsection{Retail Industry}

Estimates for CML and WOW, which are two of Australia's largest retail corporations, are such that, as in the previous results, the $\alpha$ and $\beta$ estimates are positive and significant for both 
corporations. There appears to be an asymmetric effect on the conditional duration from previous price changes as the $\delta$ estimates are negative and significant in all cases except one, namely it is not significant for CML under the exponential distribution. This would suggest that the presence of asymmetric effects would be industry dependent. In addition, the coefficients of the bid and ask volumes continue to be positive and significant. The large differences in estimates occur in the context of the asymmetric model after the inclusion of volume statistics.

\subsection{Transport and Telecommunication Industries}

The parameter estimates for QAN and TLS, which represent the air and telecommunications industries for Australia, respectively, are such that, somewhat interestingly, both the $\delta$ and $\gamma$ estimates are significant, but with opposite signs. This would suggest that a negative price shock has lower short run persistence on the conditional duration but has a positive impact on future conditional duration. In other words, a negative price change will lead to a longer duration before the next price change, but the impact will not last as long as a positive price change. Again, bid and ask volumes play important roles in determining future duration as the estimates of $\lambda_{1}$ and $\lambda_{2}$ are both positive and significant for QAN. However, the results for TLS are qualitatively identical to those of the banking industry. No evidence is found for asymmetric effects on duration from price changes, but the estimates of $\lambda_{1}$ and $\lambda_{2}$ are both positive and significant, which indicates the importance of the bid and ask volumes in predicting the duration for the next price change.

\subsection{Bootstrapped Confidence Intervals}

Section 2 showed that the QMLE based on the log-normal density is consistent and asymptotically normal for the log-ACD model. It is, however, unclear whether the same results hold when different densities are used to construct the QMLE. Moreover, although the Monte Carlo results presented in Section 3 provided support for the theoretical results, the usefulness of the asymptotic results in finite samples is still unclear from an empirical perspective. Therefore, this section compares the bootstrapped confidence intervals and the confidence intervals constructed by using the robust standard errors (asymptotic confidence intervals) of the estimates obtained in the empirical section. 
As reported in the empirical section, the diagnostic tests indicated that the standardised residuals of the Log-ACD model under different distributional assumptions are IID in all cases, but the residuals did not follow any of the assumed distributions. Therefore, bootstrapping techniques can be used to provide an accurate approximation of the underlying distribution of the QMLE in finite samples. Thus, comparing the bootstrapped confidence intervals and the asymptotic confidence intervals will provide insight into the applicability of asymptotic normality in finite samples. The bootstrapped confidence intervals are constructed by using the percentile method, as proposed in Efron and Tibshirani (1993).

Tables $4 \mathrm{a}-4 \mathrm{~d}$ provide the estimates of the Log-ACD model, their bootstrapped confidence intervals and the asymptotic confidence intervals for the eight companies using four different densities, namely the log-normal, Weibull, exponential and normal distributions. The Generalised Gamma distribution is not used in this section due to the computational difficulties, as mentioned previously. The widths of both confidence intervals are also presented for purposes of comparison. In addition, the asymptotic confidence intervals assume symmetry, whereas bootstrapped confidence intervals do not impose such an assumption. Therefore, a measure of asymmetry is also presented in Tables $4 \mathrm{a}-4 \mathrm{~d}$ to examine the symmetric property of the confidence intervals in finite samples.

Let $\hat{\theta}$ denote the QMLE of $\theta$, and let $\theta_{L}$ and $\theta_{U}$, respectively, denote the lower and upper bounds of the confidence interval for $\hat{\theta}$. A simple measure of asymmetry can be calculated as

$$
\tau=\left(\theta_{U}-\hat{\theta}\right)-\left(\hat{\theta}-\theta_{L}\right)
$$

Obviously, if the confidence interval is symmetric, then $\tau=0$; if $\tau>0 \quad(\tau<0)$, then the confidence interval is positively (negatively) skewed.

As shown in Tables $4 \mathrm{a}$ and $4 \mathrm{~d}$, the asymptotic confidence intervals and the bootstrapped confidence intervals from the log-normal and normal densities are reasonably symmetric. In addition, the bootstrapped confidence intervals are subsets of the asymptotic confidence intervals. This demonstrates efficiency gain in the estimates from the bootstrapping method.

However, in the cases of the Weibull and Exponential densities, the symmetric assumption does not hold in some cases, especially for the estimates of $\omega$ and $\beta$, as shown in Tables $4 \mathrm{~b}$ and $4 \mathrm{c}$. 
The presence of asymmetry leads to the bootstrapped confidence intervals being wider than the asymptotic confidence intervals. This suggests that the asymptotic confidence intervals may provide a poor approximation in finite samples when the Weibull and Exponential distributions are used to obtain the QMLE.

\section{Concluding Remarks}

The paper examined the finite sample properties of the Quasi Maximum Likelihood Estimator (QMLE) of the Logarithmic Autoregressive Conditional Duration (Log-ACD) model. The structural and statistical properties of the log-ACD model were examined by establishing the relationship between the Log-ACD model and the Autoregressive Moving Average (ARMA) time series model. The theoretical results developed in the paper were evaluated using Monte Carlo experiments for four different types of distributions, namely the Weibull, exponential, generalised gamma and log-normal, all of which produced the required positive standardised residuals.

Two asymmetric Log-ACD models were developed to capture any asymmetric properties of the conditional duration. The objective was to capture any asymmetric or 'leverage' type behaviour in the conditional expected duration. The results suggested that the conditional expected duration was not only persistent, but also reacted to information shocks in asset returns in the form of positive versus negative price movements. It is frequently argued that trading activity and asset return volatility are correlated with the intensity of market information flow, which means that trading becomes more intensive as the information flow intensifies. This also means that increases in information flows will tend to be associated with shorter durations.

It has also been suggested that investors trading on information might try to hide the fact that they have information by trading in small parcels. The analysis of volume effects was generally consistent with such an empirical observation as bid and ask volumes appeared to be positively correlated with price durations. The empirical results are consistent with the argument that the intensity of information disclosure impacts on both price durations and trading volumes. 


\section{Appendix}

Proof of Proposition 1: From the second equation in (4):

$$
\begin{aligned}
\phi_{i} & =w+\sum_{j=1}^{p} \alpha_{j} \log x_{i-j}+\sum_{j=1}^{q} \beta_{j} \phi_{i-j} \\
& =w+\sum_{j=1}^{r} \alpha_{j} \log x_{i-j}+\sum_{j=1}^{r} \beta_{j} \phi_{i-j}
\end{aligned}
$$

where $\alpha_{p+1}=\ldots=\alpha_{q}=0$, if $q>p$ and $\beta_{q+1}=\ldots=\beta_{p}=0$, if $q<p$. Notice that $\mu_{i}=\log x_{i}-\phi_{i}$, so the last equation above can be rewritten as follows:

$$
\begin{aligned}
\log x_{i} & =w+\sum_{j=1}^{r} \alpha_{j} \log x_{i-j}+\sum_{j=1}^{r} \beta_{j} \phi_{i-j}+\log x_{i}-\phi_{i} \\
& =w+\sum_{j=1}^{r} \alpha_{j} \log x_{i-j}+\sum_{j=1}^{r} \beta_{j} \phi_{i-j}+\mu_{i} \\
& =w+\sum_{j=1}^{r} \alpha_{j} \log x_{i-j}+\sum_{j=1}^{r} \beta_{j} \log x_{i-j}+\sum_{j=1}^{r} \beta_{j} \phi_{i-j}-\sum_{j=1}^{r} \beta_{j} \log x_{i-j}+\mu_{i} \\
& =w+\sum_{j=1}^{r}\left(\alpha_{j}+\beta_{j}\right) \log x_{i-j}-\sum_{j=1}^{r} \beta_{j}\left(\log x_{i}-\phi_{i-j}\right)+\mu_{i},
\end{aligned}
$$

and hence, $\log x_{i}$ can be expressed as

$$
\log x_{i}=w+\sum_{j=1}^{r} \delta_{j} \log x_{i-j}+\sum_{j=1}^{r} \theta_{j} \mu_{i-j}+\mu_{i}
$$

where $\delta_{j}=\alpha_{j}+\beta_{j}$ and $\theta_{j}=-\beta_{j}$. If $E\left(\mu_{i}\right) \neq 0$, the last equation can be rewritten as

$$
\begin{aligned}
\log x_{i} & =w+\sum_{j=1}^{r} \theta_{j} E\left(\mu_{i}\right)+E\left(\mu_{i}\right)+\sum_{j=1}^{r} \delta_{j} \log x_{i-j}+\sum_{j=1}^{r} \theta_{j}\left(\mu_{i-j}-E\left(\mu_{i}\right)\right)+\left(\mu_{i}-E\left(\mu_{i}\right)\right) \\
& =\tilde{w}+\sum_{j=1}^{r} \delta_{j} \log x_{i-j}+\sum_{j=1}^{r} \theta_{j} \xi_{i-j}+\xi_{i}
\end{aligned}
$$

where $\xi_{i}=\mu_{i}-E\left(\mu_{i}\right)$, so that $\xi_{i} \sim \operatorname{iid}\left(0, \sigma_{\xi}^{2}\right)$ and $\tilde{w}=w+\sum_{j=1}^{r} \theta_{j} E\left(\mu_{i}\right)+E\left(\mu_{i}\right)$ 
Proof of Proposition 2: It is sufficient to verify the following conditions of Theorem 4.1.2 in Amemiya (1985):

A1. $\Lambda$ is an open subset of the Euclidean Space $R^{p+q+1}$, such that $\lambda_{0} \in \lambda$.

A2. $l(\lambda)$ is a measurable function of $x_{i}$ for all $i$ and for all $\lambda \in \Lambda$. Moreover, $\partial l / \partial \lambda$ exists and is continuous in an open neighbourhood of $\lambda_{0}$.

A3. $T^{-1} l(\lambda)$ converges to a non-stochastic function in probability uniformly in $\lambda$ in a open neighbourhood of $\lambda_{0}$, and the non-stochastic function attains a strict local maximum at $\lambda_{0}$.

A1 is satisfied automatically by Assumption 1. For A2, notice that

$\frac{\partial l}{\partial \lambda}=\left(\begin{array}{c}\frac{\partial l}{\partial s^{2}} \\ \frac{\partial l}{\partial \theta}\end{array}\right)$

where

$\frac{\partial l}{\partial s^{2}}=-\frac{T}{2 s^{2}}+\frac{1}{2} \sum_{i=1}^{T} \frac{\left(\log x_{i}-\phi_{i}\right)^{2}}{s^{4}}$ and $\frac{\partial l}{\partial \theta}=\sum_{i=1}^{T} \frac{\log x_{i}-\phi_{i}}{s^{2}} \frac{\partial \phi_{i}}{\partial \theta}$

Therefore, under Assumptions (1) - (3), $\frac{\partial l}{\partial \lambda}$ exists and is continuous for all $\lambda \in \Lambda$, and $l(\lambda)$ is a measurable function of $x_{i}$ for all $i$ and for all $\lambda \in \Lambda$.

For A3, let $g_{i}(\lambda)=l_{i}(\lambda)-E\left[l_{i}(\lambda)\right]$, and it is obvious that $E\left[g_{i}(\lambda)\right]=0$. Under Assumptions (1) and (2), $E\left[\sup _{\lambda \in \Lambda} g_{i}(\lambda)\right]<\infty$, so that $\limsup _{T \rightarrow \infty}\left|\sum_{\lambda \in \Lambda}^{T} l_{i=1}(\lambda)-E\left[l_{i}(\lambda)\right]\right|=0$, a.s.

Now, consider the following maximisation problem:

$$
\begin{aligned}
\max _{\lambda \in \Lambda} l(\lambda)-l\left(\lambda_{0}\right) & =\max _{\lambda \in \Lambda} E\left[l_{i}(\lambda)-l_{i}\left(\lambda_{0}\right)\right] \\
& =\max _{\lambda \in \Lambda} E\left[\frac{1}{2} \log \frac{s_{0}^{2}}{s^{2}}-\frac{1}{2}\left\{\frac{\left(\log x_{i}-\phi_{i}(\theta)\right)^{2}}{s^{2}}-\frac{\left(\log x_{i}-\phi_{i}\left(\theta_{0}\right)\right)^{2}}{s_{0}^{2}}\right\}\right] \\
& =\max _{\lambda \in \Lambda} E\left[\frac{1}{2} \log \frac{s_{0}^{2}}{s^{2}}-\frac{1}{2}\left\{\frac{\left(\phi_{i}\left(\theta_{0}\right)-\phi_{i}(\theta)\right)^{2}+\left(\log \eta_{i}\right)^{2}+2 \log \eta_{i}\left(\phi_{i}\left(\theta_{0}\right)-\phi_{i}(\theta)\right)}{s^{2}}-\frac{\left(\log \eta_{i}\right)^{2}}{s_{0}^{2}}\right\}\right] \\
& =\max _{\lambda \in \Lambda} \frac{1}{2}\left(\log \frac{s_{0}^{2}}{s^{2}}-\frac{s_{0}^{2}}{s^{2}}\right)-\frac{1}{2} \frac{E\left(\phi_{i}\left(\theta_{0}\right)-\phi_{i}(\theta)\right)^{2}}{s^{2}} \\
& \text { by Assumption } 4 \\
& =\max _{\lambda \in \Lambda} R_{1}\left(s^{2}\right)-R_{2}\left(\theta, s^{2}\right)
\end{aligned}
$$


where $R_{1}\left(s^{2}\right)=\frac{1}{2}\left(\log \frac{s_{0}^{2}}{s^{2}}-\frac{s_{0}^{2}}{s^{2}}\right)$ and $R_{2}\left(\theta, s^{2}\right)=\frac{1}{2} \frac{E\left(\phi_{i}\left(\theta_{0}\right)-\phi_{i}(\theta)\right)^{2}}{s^{2}}$. Notice that $R_{1}\left(s^{2}\right)<0, \forall s^{2}$ as $\forall x>0, \quad m(x)=\log x-x \leq 0$, and $m(x)$ is maximised at $x=1$, so that $s^{2}=s_{0}^{2}$. Moreover, $R_{2}\left(\theta, s^{2}\right) \geq 0 \forall \theta, s^{2}$, so that the solution to the maximisation problem is $\theta$ such that $R_{2}\left(\theta, s^{2}\right)=0$, which will occur if and only if $\phi_{i}\left(\theta_{0}\right)=\phi_{i}(\theta)$ for all $i$, which implies $\theta=\theta_{0}$. Therefore, the likelihood function converges to a non-stochastic function which attains a strict local maximum at $\lambda_{0}$. These imply Conditions A1 to A3 are satisfied under Assumptions (1)-(4), and hence $\hat{\lambda} \stackrel{p}{\rightarrow} \lambda_{0}$. This completes the proof.

Proof of Proposition 3: Given the result in Proposition 2, it is sufficient to verify the following conditions of Theorem 4.1.3 in Amemiya (1985):

B1. $\frac{\partial^{2} l}{\partial \lambda \partial \lambda^{\prime}}$ exists and is continuous in an open, convex neighbourhood of $\theta_{0}$.

B2. $\left.T^{-1} \frac{\partial^{2} l}{\partial \lambda \partial \lambda^{\prime}}\right|_{\lambda=\lambda_{T}}$ converges to a finite non-singular matrix $A\left(\lambda_{0}\right)=\left.\lim _{T \rightarrow \infty} T^{-1} E\left(\frac{\partial^{2} l}{\partial \lambda \partial \lambda^{\prime}}\right)\right|_{\lambda=\lambda_{0}}$ in probability for any sequence $\lambda_{T}$, such that plim $\lambda_{T}=\lambda_{0}$.

B3. $\left.T^{-1 / 2} \frac{\partial l}{\partial \lambda}\right|_{\lambda=\lambda_{0}} \rightarrow N\left(0, B\left(\lambda_{0}\right)\right)$, where $B\left(\lambda_{0}\right)=\left.\lim _{T \rightarrow \infty} T^{-1} E\left(\frac{\partial l}{\partial \lambda} \frac{\partial l}{\partial \lambda^{\prime}}\right)\right|_{\lambda=\lambda_{0}}$.

First, consider the following first and second order partial derivatives $\forall i=1, \ldots, T$ :

$$
\begin{aligned}
& \frac{\partial l_{i}}{\partial s^{2}}=-\frac{1}{2 s^{2}}+\frac{1}{2 s^{4}}\left(\log x_{i}-\phi_{i}\right)^{2} ; \frac{\partial l_{i}}{\partial \theta}=\frac{\log x_{i}-\phi_{i}}{s^{2}} \frac{\partial \phi_{i}}{\partial \theta} \\
& \frac{\partial^{2} l_{i}}{\partial\left(s^{2}\right)^{2}}=\frac{1}{2 s^{4}}-\frac{1}{2 s^{6}}\left(\log x_{i}-\phi_{i}\right)^{2} ; \\
& \frac{\partial^{2} l_{i}}{\partial \theta \partial \theta^{\prime}}=-\frac{\partial l_{i}}{\partial \theta} \frac{\partial l_{i}}{\partial \theta^{\prime}} \frac{1}{s^{2}}+\frac{\log x_{i}-\phi_{i}}{s^{2}} \frac{\partial^{2} \phi_{i}}{\partial \theta \partial \theta^{\prime}} ; \\
& \frac{\partial^{2} l_{i}}{\partial s^{2} \partial \theta^{\prime}}=-\frac{1}{s^{2}}\left(\log x_{i}-\phi_{i}\right) \frac{\partial \phi_{i}}{\partial \theta^{\prime}} .
\end{aligned}
$$

Under Assumption 1, B1 is satisfied by examining the derivatives above directly. For B2, it is sufficient to verify that

$$
\limsup _{T \rightarrow \infty} \frac{1}{T \in \Lambda}\left\|\left.\sum_{i=1}^{T} \frac{\partial^{2} l_{i}}{\partial \lambda \partial \lambda^{\prime}}\right|_{\lambda_{T}}-E\left(\left.\frac{\partial^{2} l_{i}}{\partial \lambda \partial \lambda^{\prime}}\right|_{\lambda_{0}}\right)\right\|=0
$$

where 
$\frac{\partial^{2} l_{i}}{\partial \lambda \partial \lambda^{\prime}}=\left(\begin{array}{cc}\frac{\partial^{2} l_{i}}{\partial\left(s^{2}\right)^{2}} & \frac{\partial^{2} l_{i}}{\partial s^{2} \partial \theta^{\prime}} \\ \frac{\partial^{2} l_{i}}{\partial \theta \partial s^{2}} & \frac{\partial^{2} l_{i}}{\partial \theta \partial \theta^{\prime}}\end{array}\right)$.

Now, under Assumption 4, it follows that

$\frac{\partial^{2} l_{i}}{\partial\left(s^{2}\right)^{2}}-E\left(\frac{\partial^{2} l_{i}}{\partial\left(s^{2}\right)^{2}}\right)=\frac{1}{2 s^{6}}\left(\left(\log \eta_{i}\right)^{2}-1\right)$

and, under Assumptions 2 and 4, it follows that

$$
\begin{aligned}
\limsup _{T \rightarrow \infty} \frac{1}{T}\left\|\sum_{i=1}^{T} \frac{\partial^{2} l_{i}}{\partial\left(s^{2}\right)^{2}}-E\left(\frac{\partial^{2} l_{i}}{\partial\left(s^{2}\right)^{2}}\right)\right\| & =\limsup _{T \rightarrow \infty} \frac{1}{T}\left\|\sum_{i=1}^{T} \frac{1}{2 s^{6}}\left(\left(\log \eta_{i}\right)^{2}-1\right)\right\| \\
& =\limsup _{T \rightarrow \infty}\left\|\frac{1}{2 \sin ^{6}}\left[\sum_{i=1}^{T}\left(\frac{\left(\log \eta_{i}\right)^{2}}{T}\right)-1\right]\right\| \\
& =0 \quad \text { a.s. }
\end{aligned}
$$

Furthermore, under Assumptions 2, 3 and 4, we have $\frac{\partial^{2} l_{i}}{\partial \theta \partial \theta^{\prime}}-E\left(\frac{\partial^{2} l_{i}}{\partial \theta \partial \theta^{\prime}}\right)=\left[E\left(\frac{\partial \phi_{i}}{\partial \theta} \frac{\partial \phi_{i}}{\partial \theta^{\prime}}\right)-\frac{\partial \phi_{i}}{\partial \theta} \frac{\partial \phi_{i}}{\partial \theta^{\prime}}\right] \frac{1}{s^{2}}+\frac{\log x_{i}-\phi_{i}}{s^{2}} \frac{\partial^{2} \phi_{i}}{\partial \theta \partial \theta^{\prime}}$.

Notice that

$\lim _{T \rightarrow \infty} \frac{1}{T} \sum_{i=1}^{T} \frac{\partial \phi_{i}}{\partial \theta} \frac{\partial \phi_{i}}{\partial \theta^{\prime}}-E\left(\frac{\partial \phi_{i}}{\partial \theta} \frac{\partial \phi_{i}}{\partial \theta^{\prime}}\right) \quad$ a.s.

and

$$
\begin{aligned}
\lim _{T \rightarrow \infty} \frac{1}{T} \sum_{i=1}^{T} \frac{\log x_{i}-\phi_{i}}{s^{2}} \frac{\partial^{2} \phi_{i}}{\partial \theta \partial \theta^{\prime}} & =E\left(\frac{\log \eta_{i}}{s^{2}} \frac{\partial^{2} \phi_{i}}{\partial \theta \partial \theta^{\prime}}\right) \\
& =\frac{1}{s^{2}} E\left(\log \eta_{i}\right) E\left(\frac{\partial^{2} \phi_{i}}{\partial \theta \partial \theta^{\prime}}\right) \\
& =0 \text { a.s. }
\end{aligned}
$$

Therefore, 


$$
\begin{aligned}
\limsup _{T \rightarrow \infty} \frac{1}{T}\left\|\left.\sum_{i=1}^{T} \frac{\partial^{2} l_{i}}{\partial \theta \partial \theta^{\prime}}\right|_{\theta_{T}}-E\left(\left.\frac{\partial^{2} l_{i}}{\partial \theta \partial \theta^{\prime}}\right|_{\theta_{0}}\right)\right\| & =\limsup _{T \rightarrow \infty} \frac{1}{T}\left\|\sum_{i=1}^{T}\left[E\left(\frac{\partial \phi_{i}}{\partial \theta} \frac{\partial \phi_{i}}{\partial \theta^{\prime}}\right)-\frac{\partial \phi_{i}}{\partial \theta} \frac{\partial \phi_{i}}{\partial \theta^{\prime}}\right] \frac{1}{s^{2}}+\frac{\log x_{i}-\phi_{i}}{s^{2}} \frac{\partial^{2} \phi_{i}}{\partial \theta \partial \theta^{\prime}}\right\| \\
& =\limsup _{T \rightarrow \infty} \| \frac{1}{\lambda \in \Lambda}\left(E\left(\frac{\partial \phi_{i}}{\partial \theta} \frac{\partial \phi_{i}}{\partial \theta^{\prime}}\right)-\sum_{i=1}^{T}\left[\frac{1}{T} \frac{\partial \phi_{i}}{\partial \theta} \frac{\partial \phi_{i}}{\partial \theta^{\prime}}\right]\right)+\frac{1}{T} \sum_{i=1}^{T} \frac{\log \eta_{i}}{s^{2}} \frac{\partial^{2} \phi_{i}}{\partial \theta \partial \theta^{\prime} \|} \\
& =0 \text { a.s. }
\end{aligned}
$$

Finally, notice that

$$
\frac{\partial^{2} l_{i}}{\partial s^{2} \partial \theta^{\prime}}-E\left(\frac{\partial^{2} l_{i}}{\partial s^{2} \partial \theta^{\prime}}\right)=-\frac{1}{s^{4}} \log \eta_{i} \frac{\partial \phi_{i}}{\partial \theta^{\prime}}
$$

so that

$$
\begin{aligned}
\limsup _{T \rightarrow \infty} \frac{1}{T}\left\|\left.\sum_{i=1}^{T} \frac{\partial^{2} l_{i}}{\partial s^{2} \partial \theta^{\prime}}\right|_{\lambda_{T}}-E\left(\left.\frac{\partial^{2} l_{i}}{\partial s^{2} \partial \theta^{\prime}}\right|_{\lambda_{0}}\right)\right\| & =\lim _{T \rightarrow \infty} \sup _{\lambda \in \Lambda} \frac{1}{T}\left\|\sum_{i=1}^{T}-\frac{1}{s^{4}} \log \eta_{i} \frac{\partial \phi_{i}}{\partial \theta^{\prime}}\right\| \\
& =\lim _{T \rightarrow \infty} \sup _{\lambda \in \Lambda}\left\|-\frac{1}{s^{4}} \sum_{i=1}^{T} \frac{\log \eta_{i}}{T} \frac{\partial \phi_{i}}{\partial \theta^{\prime}}\right\| \\
& =\sup _{\lambda \in \Lambda}\left\|-\frac{1}{s^{4}} E\left(\log \eta_{i} \frac{\partial \phi_{i}}{\partial \theta^{\prime}}\right)\right\| \\
& =\sup _{\lambda \in \Lambda}\left\|-\frac{1}{s^{4}} E\left(\log \eta_{i}\right) E\left(\frac{\partial \phi_{i}}{\partial \theta^{\prime}}\right)\right\| \\
& =0 .
\end{aligned}
$$

Hence, B2 is satisfied. For B3, let $S_{T}=\sum_{i=1}^{T} c^{\prime} \frac{\partial l_{i}}{\partial \lambda}$, where $c$ is a constant vector with the same dimension as $\lambda$. Notice that $S_{T}$ is a martingale array with respect to the information set, $I_{t-1}$, so that

$$
E\left(\frac{S_{T}^{2}}{T}\right)=c^{\prime} E\left[\frac{\partial l_{i}}{\partial \lambda} \frac{\partial l_{i}}{\partial \lambda^{\prime}}\right] c>0
$$

by the given assumptions. Using the Central Limit Theorem of Stout (1974),

$$
\frac{1}{T^{1 / 2}} \sum_{i=1}^{T} \frac{\partial l_{i}}{\partial \lambda} \stackrel{d}{\longrightarrow} N\left(0, B\left(\lambda_{0}\right)\right)
$$

where $B\left(\lambda_{0}\right)=\lim _{T \rightarrow \infty} \frac{1}{T} E\left(\left.\frac{\partial l}{\partial \lambda} \frac{\partial l}{\partial \lambda^{\prime}}\right|_{\lambda=\lambda_{0}}\right)$. Therefore, B3 is satisfied, and hence all the conditions of Theorem 4.1.3 in Amemiya (1985) have been established. This completes the proof. 
Table 1. Summary Statistics for Eight Companies on the Australian Stock Exchange

\begin{tabular}{|c|cccccccc|}
\hline Statistics & ANZ & CBA & BHP & WPL & CML & WOW & TLS & QAN \\
\hline Mean & 80.1535 & 57.55475 & 100.3229 & 133.8996 & 287.579 & 136.1386 & 461.3966 & 463.057 \\
Median & 36 & 27 & 32 & 52 & 109 & 53 & 123 & 152 \\
Maximum & 18485 & 18316 & 18560 & 18191 & 18229 & 18220 & 18302 & 15798 \\
Minimum & 1 & 1 & 1 & 1 & 1 & 1 & 1 & 1 \\
Std. Dev. & 232.1636 & 168.9323 & 312.1668 & 367.0297 & 604.7731 & 407.2284 & 973.3416 & 915.73 \\
Skewness & 51.39532 & 78.25914 & 33.61695 & 29.96407 & 11.50926 & 26.17681 & 6.607736 & 6.082173 \\
Kurtosis & 3739.022 & 8343.062 & 1721.953 & 1363.638 & 261.3184 & 990.3336 & 78.29639 & 64.82925 \\
Observations & 16384 & 16384 & 14854 & 11130 & 5104 & 11105 & 3172 & 3122 \\
\hline
\end{tabular}


Table 2a. True Distribution is Lognormal, Sample Size 500, Replications 3000

\begin{tabular}{|l|c|c|c|c|c|}
\hline \multicolumn{1}{|c|}{$\hat{\alpha}$} & Lognormal & Weibull & G. Gamma & Exponential & Normal \\
\hline Mean & 0.214 & 0.205 & 0.181 & 0.198 & 0.214 \\
\hline Median & 0.214 & 0.204 & 0.191 & 0.196 & 0.214 \\
\hline Maximum & 0.347 & 0.353 & 0.393 & 0.379 & 0.347 \\
\hline Minimum & 0.060 & 0.035 & -0.028 & 0.011 & 0.060 \\
\hline Std. Dev. & 0.035 & 0.039 & 0.067 & 0.047 & 0.035 \\
\hline Skewness & 0.025 & 0.104 & -0.788 & 0.176 & 0.025 \\
\hline Kurtosis & 3.179 & 3.127 & 3.688 & 3.221 & 3.179 \\
\hline
\end{tabular}

\begin{tabular}{|l|c|c|c|c|c|}
\hline \multicolumn{1}{|c|}{$t(\hat{\alpha})$} & Lognormal & Weibull & G. Gamma & Exponential & Normal \\
\hline Mean & 0.369 & 0.066 & -7.656 & -0.142 & 0.185 \\
\hline Median & 0.408 & 0.121 & -0.084 & -0.079 & 0.232 \\
\hline Maximum & 3.739 & 3.412 & 3.242 & 6.725 & 3.517 \\
\hline Minimum & -4.598 & -5.903 & $-1.620 \mathrm{E}+04$ & -15.993 & -4.578 \\
\hline Std. Dev. & 1.027 & 1.107 & 299.533 & 1.253 & 1.060 \\
\hline Skewness & -0.196 & -0.290 & -52.959 & -1.079 & -0.208 \\
\hline Kurtosis & 3.374 & 3.443 & 2857.967 & 13.049 & 3.278 \\
\hline Jarque-Bera & 36.600 & 66.504 & $1.018 \mathrm{E}+09$ & $1.317 \mathrm{E}+04$ & 31.216 \\
\hline Probability & 0.000 & 0.000 & 0.000 & 0.000 & 0.000 \\
\hline
\end{tabular}

\begin{tabular}{|l|c|c|c|c|c|}
\hline \multicolumn{1}{|c|}{$\hat{\beta}$} & Lognormal & Weibull & G. Gamma & Exponential & Normal \\
\hline Mean & 0.646 & 0.669 & 0.482 & 0.681 & 0.646 \\
\hline Median & 0.654 & 0.676 & 0.675 & 0.692 & 0.654 \\
\hline Maximum & 0.868 & 0.882 & 0.940 & 0.961 & 0.868 \\
\hline Minimum & 0.084 & 0.154 & -1.026 & -0.076 & 0.084 \\
\hline Std. Dev. & 0.071 & 0.076 & 0.544 & 0.099 & 0.071 \\
\hline Skewness & -0.868 & -0.738 & -2.241 & -1.991 & -0.868 \\
\hline Kurtosis & 5.620 & 4.617 & 6.223 & 13.953 & 5.620 \\
\hline
\end{tabular}

\begin{tabular}{|l|c|c|c|c|c|}
\hline \multicolumn{1}{|c|}{$t(\hat{\beta})$} & Lognormal & Weibull & G. Gamma & Exponential & Normal \\
\hline Mean & -0.686 & -0.296 & -134.088 & -1.482 & -0.478 \\
\hline Median & -0.730 & -0.374 & -0.215 & -0.089 & -0.530 \\
\hline Maximum & 4.133 & 5.433 & 14.251 & 9.021 & 4.223 \\
\hline Minimum & -3.784 & -3.815 & $-1.131 \mathrm{E}+05$ & $-3.973 \mathrm{E}+03$ & -3.691 \\
\hline Std. Dev. & 0.956 & 1.083 & $3.316 \mathrm{E}+03$ & 72.677 & 1.018 \\
\hline Skewness & 0.323 & 0.384 & -29.428 & -54.546 & 0.279 \\
\hline Kurtosis & 3.764 & 3.582 & 906.741 & $2.981 \mathrm{E}+03$ & 3.517 \\
\hline Jarque-Bera & 124.676 & 115.953 & $1.023 \mathrm{E}+08$ & $1.108 \mathrm{E}+09$ & 72.233 \\
\hline Probability & 0.000 & 0.000 & 0.000 & 0.000 & 0.000 \\
\hline
\end{tabular}


Table 2b. True Distribution is Lognormal, Sample Size 1000, Replications 3000

\begin{tabular}{|l|c|c|c|c|c|}
\hline \multicolumn{1}{|c|}{$\hat{\alpha}$} & Lognormal & Weibull & G. Gamma & Exponential & Normal \\
\hline Mean & 0.207 & 0.202 & 0.190 & 0.199 & 0.207 \\
\hline Median & 0.207 & 0.203 & 0.196 & 0.198 & 0.207 \\
\hline Maximum & 0.302 & 0.305 & 0.351 & 0.317 & 0.302 \\
\hline Minimum & 0.123 & 0.119 & -0.022 & 0.100 & 0.123 \\
\hline Std. Dev. & 0.025 & 0.028 & 0.051 & 0.033 & 0.025 \\
\hline Skewness & 0.108 & 0.082 & -1.694 & 0.127 & 0.108 \\
\hline Kurtosis & 3.173 & 2.981 & 7.362 & 3.046 & 3.173 \\
\hline
\end{tabular}

\begin{tabular}{|l|c|c|c|c|c|}
\hline \multicolumn{1}{|c|}{$t(\hat{\alpha})$} & Lognormal & Weibull & G. Gamma & Exponential & Normal \\
\hline Mean & 0.275 & 0.035 & -9.491 & -0.152 & 0.128 \\
\hline Median & 0.302 & 0.101 & -0.101 & -0.065 & 0.158 \\
\hline Maximum & 3.816 & 3.297 & 3.785 & 3.489 & 3.609 \\
\hline Minimum & -4.003 & -4.052 & $-2.484 \mathrm{E}+04$ & -103.182 & -4.363 \\
\hline Std. Dev. & 1.023 & 1.081 & 453.635 & 2.215 & 1.056 \\
\hline Skewness & -0.130 & -0.241 & -54.683 & -33.697 & -0.150 \\
\hline Kurtosis & 3.241 & 3.149 & $2.993 \mathrm{E}+03$ & $1.564 \mathrm{E}+03$ & 3.196 \\
\hline Jarque-Bera & 15.799 & 31.736 & $1.120 \mathrm{E}+09$ & $3.050 \mathrm{E}+08$ & 16.067 \\
\hline Probability & 0.000 & 0.000 & 0.000 & 0.000 & 0.000 \\
\hline
\end{tabular}

\begin{tabular}{|l|c|c|c|c|c|}
\hline \multicolumn{1}{|c|}{$\hat{\beta}$} & Lognormal & Weibull & G. Gamma & Exponential & Normal \\
\hline Mean & 0.675 & 0.686 & 0.601 & 0.693 & 0.675 \\
\hline Median & 0.677 & 0.689 & 0.692 & 0.697 & 0.677 \\
\hline Maximum & 0.819 & 0.828 & 0.879 & 0.868 & 0.819 \\
\hline Minimum & 0.496 & 0.465 & -1.010 & 0.370 & 0.496 \\
\hline Std. Dev. & 0.045 & 0.050 & 0.383 & 0.059 & 0.045 \\
\hline Skewness & -0.311 & -0.397 & -3.792 & -0.559 & -0.311 \\
\hline Kurtosis & 3.312 & 3.453 & 15.789 & 4.044 & 3.312 \\
\hline
\end{tabular}

\begin{tabular}{|l|c|c|c|c|c|}
\hline \multicolumn{1}{|c|}{$t(\hat{\beta})$} & Lognormal & Weibull & G. Gamma & Exponential & Normal \\
\hline Mean & -0.493 & -0.181 & -85.761 & 0.013 & -0.324 \\
\hline Median & -0.539 & -0.258 & -0.120 & -0.026 & -0.383 \\
\hline Maximum & 4.437 & 5.454 & 5.834 & 5.251 & 4.825 \\
\hline Minimum & -3.571 & -3.381 & $-1.862 \mathrm{E}+05$ & $-4.328 \mathrm{E}+00$ & -3.478 \\
\hline Std. Dev. & 0.989 & 1.073 & $3.471 \mathrm{E}+03$ & 1.162 & 1.042 \\
\hline Skewness & 0.324 & 0.403 & -51.878 & 0.317 & 0.324 \\
\hline Kurtosis & 3.755 & 3.633 & $2.765 \mathrm{E}+03$ & $3.735 \mathrm{E}+00$ & 3.635 \\
\hline Jarque-Bera & 123.900 & 131.321 & $9.550 \mathrm{E}+08$ & 117.927 & 102.968 \\
\hline Probability & 0.000 & 0.000 & 0.000 & 0.000 & 0.000 \\
\hline
\end{tabular}


Table 2c. True Distribution is Lognormal, Sample Size 3000, Replications 3000

\begin{tabular}{|l|c|c|c|c|c|}
\hline \multicolumn{1}{|c|}{$\hat{\alpha}$} & Lognormal & Weibull & G. Gamma & Exponential & Normal \\
\hline Mean & 0.203 & 0.201 & 0.189 & 0.200 & 0.203 \\
\hline Median & 0.203 & 0.201 & 0.198 & 0.199 & 0.203 \\
\hline Maximum & 0.260 & 0.262 & 0.279 & 0.269 & 0.260 \\
\hline Minimum & 0.158 & 0.145 & -0.005 & 0.132 & 0.158 \\
\hline Std. Dev. & 0.014 & 0.016 & 0.048 & 0.019 & 0.014 \\
\hline Skewness & 0.058 & 0.070 & -2.971 & 0.085 & 0.058 \\
\hline Kurtosis & 2.973 & 3.073 & 11.900 & 3.197 & 2.973 \\
\hline
\end{tabular}

\begin{tabular}{|l|c|c|c|c|c|}
\hline \multicolumn{1}{|c|}{$t(\hat{\alpha})$} & Lognormal & Weibull & G. Gamma & Exponential & Normal \\
\hline Mean & 0.189 & 0.029 & -96.143 & -0.062 & 0.092 \\
\hline Median & 0.178 & 0.063 & -0.058 & -0.014 & 0.094 \\
\hline Maximum & 3.546 & 3.288 & 3.780 & 3.875 & 3.338 \\
\hline Minimum & -3.234 & -4.130 & $-2.562 \mathrm{E}+05$ & -11.657 & -3.551 \\
\hline Std. Dev. & 1.010 & 1.057 & $4.691 \mathrm{E}+03$ & 1.133 & 1.008 \\
\hline Skewness & -0.014 & -0.139 & -54.278 & -0.415 & -0.078 \\
\hline Kurtosis & 2.953 & 3.131 & $2.962 \mathrm{E}+03$ & 6.687 & 2.974 \\
\hline Jarque-Bera & 0.381 & 11.858 & $1.100 \mathrm{E}+09$ & $1.785 \mathrm{E}+03$ & 3.135 \\
\hline Probability & 0.826 & 0.003 & 0.000 & 0.000 & 0.209 \\
\hline
\end{tabular}

\begin{tabular}{|l|c|c|c|c|c|}
\hline \multicolumn{1}{|c|}{$\hat{\beta}$} & Lognormal & Weibull & G. Gamma & Exponential & Normal \\
\hline Mean & 0.691 & 0.695 & 0.603 & 0.697 & 0.691 \\
\hline Median & 0.691 & 0.696 & 0.696 & 0.698 & 0.691 \\
\hline Maximum & 0.770 & 0.792 & 0.807 & 0.811 & 0.770 \\
\hline Minimum & 0.587 & 0.567 & -1.004 & 0.550 & 0.587 \\
\hline Std. Dev. & 0.025 & 0.027 & 0.390 & 0.032 & 0.025 \\
\hline Skewness & -0.150 & -0.160 & -3.834 & -0.212 & -0.150 \\
\hline Kurtosis & 3.134 & 3.238 & 15.818 & 3.365 & 3.134 \\
\hline
\end{tabular}

\begin{tabular}{|l|c|c|c|c|c|}
\hline \multicolumn{1}{|c|}{$t(\hat{\beta})$} & Lognormal & Weibull & G. Gamma & Exponential & Normal \\
\hline Mean & -0.331 & -0.129 & -114.526 & -0.025 & -0.207 \\
\hline Median & -0.367 & -0.171 & -0.080 & -0.018 & -0.256 \\
\hline Maximum & 3.565 & 4.636 & 4.425 & 6.207 & 3.954 \\
\hline Minimum & -3.992 & -4.136 & $-1.073 \mathrm{E}+05$ & -34.982 & -3.795 \\
\hline Std. Dev. & 1.004 & 1.051 & $2.461 \mathrm{E}+03$ & 1.297 & 1.004 \\
\hline Skewness & 0.108 & 0.274 & -35.410 & -6.329 & 0.198 \\
\hline Kurtosis & 3.043 & 3.381 & $1.395 \mathrm{E}+03$ & 178.028 & 3.161 \\
\hline Jarque-Bera & 6.067 & 55.757 & $2.430 \mathrm{E}+08$ & $3.849 \mathrm{E}+06$ & 22.945 \\
\hline Probability & 0.048 & 0.000 & 0.000 & 0.000 & 0.000 \\
\hline
\end{tabular}


Table 3a. Estimates of the Log-ACD Model for ANZ

\begin{tabular}{|c|c|c|c|c|}
\hline ANZ (ACD) & Log-Normal & Weibull & Exponential & Normal \\
\hline$\omega$ & -0.156 & -0.627 & 0.265 & -0.156 \\
\hline & {$[-8.344]$} & {$[-9.315]$} & {$[0.817]$} & {$[-8.118]$} \\
\hline$\alpha$ & 0.0800 & 0.066 & 0.049 & 0.08 \\
\hline & {$[12.052]$} & {$[10.742]$} & {$[7.038]$} & {$[12.016]$} \\
\hline$\beta$ & 0.695 & 0.648 & 0.588 & 0.695 \\
\hline & {$[22.716]$} & {$[18.016]$} & {$[14.112]$} & {$[22.271]$} \\
\hline
\end{tabular}

Table 3b. Estimates of the ALACDX Model for ANZ

\begin{tabular}{|c|c|c|c|c|}
\hline ANZ (Price) & Log-Normal & Weibull & Exponential & Normal \\
\hline$\omega$ & -0.153 & -0.626 & 0.273 & -0.153 \\
\hline & {$[-7.752]$} & {$[-9.336]$} & {$[0.812]$} & {$[-7.448]$} \\
\hline$\alpha$ & 0.080 & 0.067 & 0.049 & 0.080 \\
\hline & {$[11.721]$} & {$[11.161]$} & {$[7.157]$} & {$[11.640]$} \\
\hline$\beta$ & 0.693 & 0.645 & 0.584 & 0.693 \\
\hline & {$[21.731]$} & {$[17.714]$} & {$[9.697]$} & {$[20.961]$} \\
\hline$\delta$ & -0.007 & -0.010 & -0.008 & -0.007 \\
\hline & {$[-0.438]$} & {$[-0.625]$} & {$[-0.515]$} & {$[-0.431]$} \\
\hline
\end{tabular}

Table 3c. Estimates of the ALACD Model for ANZ

\begin{tabular}{|c|c|c|c|c|}
\hline ANZ (AACD) & Log-Normal & Weibull & Exponential & Normal \\
\hline$\omega$ & -0.156 & -0.628 & 0.265 & -0.156 \\
\hline & {$[-8.357]$} & {$[-9.372]$} & {$[0.850]$} & {$[-7.856]$} \\
\hline$\alpha$ & 0.081 & 0.065 & 0.049 & 0.081 \\
\hline & {$[9.967]$} & {$[8.327]$} & {$[6.123]$} & {$[9.485]$} \\
\hline$\beta$ & 0.695 & 0.647 & 0.588 & 0.695 \\
\hline & {$[22.774]$} & {$[18.088]$} & {$[12.388]$} & {$[21.385]$} \\
\hline$\gamma$ & -0.004 & 0.002 & 0.003 & -0.004 \\
\hline & {$[-0.341]$} & {$[0.207]$} & {$[0.016]$} & {$[-0.327]$} \\
\hline
\end{tabular}

Table 3d. Estimates of the ALACDX Model with Bid and Ask Volumes for ANZ

\begin{tabular}{|c|c|c|c|c|}
\hline ANZ (Price) & Log-Normal & Weibull & Exponential & Normal \\
\hline$\omega$ & -0.617 & -1.902 & 3.367 & -0.617 \\
\hline & {$[-1.446]$} & {$[-3.600]$} & {$[2.261]$} & {$[-1.404]$} \\
\hline$\alpha$ & 0.094 & 0.076 & 0.051 & 0.094 \\
\hline & {$[8.293]$} & {$[8.774]$} & {$[5.985]$} & {$[8.347]$} \\
\hline$\beta$ & 0.514 & 0.263 & 0.13 & 0.514 \\
\hline & {$[2.310]$} & {$[1.449]$} & {$[1.493]$} & {$[2.192]$} \\
\hline$\delta$ & -0.021 & -0.033 & -0.028 & -0.021 \\
\hline & {$[-0.844]$} & {$[-1.646]$} & {$[-1.618]$} & {$[-0.787]$} \\
\hline$\lambda_{1}$ & 0.015 & 0.026 & 0.029 & 0.015 \\
\hline & {$[1.014]$} & {$[2.316]$} & {$[4.502]$} & {$[1.012]$} \\
\hline$\lambda_{2}$ & 0.026 & 0.041 & 0.047 & 0.026 \\
\hline & {$[1.358]$} & {$[3.263]$} & {$[6.769]$} & {$[1.304]$} \\
\hline
\end{tabular}


Table 4a. Confidence Intervals of QMLE with Log-Normal Density

\begin{tabular}{|c|c|c|c|c|c|c|c|c|}
\hline ANZ & Estimates & $\begin{array}{c}\text { CI - } \\
\text { Lower }\end{array}$ & $\begin{array}{c}\text { CI - } \\
\text { Upper }\end{array}$ & $\begin{array}{l}\text { BCI - } \\
\text { Lower }\end{array}$ & $\begin{array}{l}\text { BCI - } \\
\text { Upper }\end{array}$ & $\begin{array}{c}\text { CI } \\
\text { Width }\end{array}$ & $\begin{array}{c}\text { BCI } \\
\text { Width }\end{array}$ & Asymmetry \\
\hline$\omega$ & -0.156 & -0.193 & -0.120 & -0.181 & -0.121 & 0.073 & 0.061 & 0.011 \\
\hline$\alpha$ & 0.080 & 0.067 & 0.093 & 0.068 & 0.089 & 0.026 & 0.021 & -0.003 \\
\hline$\beta$ & 0.695 & 0.635 & 0.754 & 0.652 & 0.753 & 0.120 & 0.102 & 0.016 \\
\hline $\mathrm{CBA}$ & Estimates & $\begin{array}{c}\text { CI - } \\
\text { Lower }\end{array}$ & $\begin{array}{c}\text { CI - } \\
\text { Upper }\end{array}$ & $\begin{array}{l}\text { BCI - } \\
\text { Lower }\end{array}$ & $\begin{array}{l}\text { BCI - } \\
\text { Upper }\end{array}$ & $\begin{array}{c}\text { CI } \\
\text { Width }\end{array}$ & $\begin{array}{c}\text { BCI } \\
\text { Width }\end{array}$ & Asymmetry \\
\hline$\omega$ & -0.161 & -0.208 & -0.113 & -0.192 & -0.133 & 0.095 & 0.060 & -0.004 \\
\hline$\alpha$ & 0.091 & 0.076 & 0.106 & 0.081 & 0.103 & 0.031 & 0.022 & 0.001 \\
\hline$\beta$ & 0.671 & 0.591 & 0.751 & 0.620 & 0.721 & 0.160 & 0.102 & -0.001 \\
\hline
\end{tabular}

\begin{tabular}{|c|c|c|c|c|c|c|c|c|}
\hline BHP & Estimates & $\begin{array}{c}\text { CI - } \\
\text { Lower }\end{array}$ & $\begin{array}{c}\text { CI - } \\
\text { Upper }\end{array}$ & $\begin{array}{c}\text { BCI - } \\
\text { Lower }\end{array}$ & $\begin{array}{c}\text { BCI - } \\
\text { Upper }\end{array}$ & $\begin{array}{c}\text { CI } \\
\text { Width }\end{array}$ & $\begin{array}{c}\text { BCI } \\
\text { Width }\end{array}$ & Asymmetry \\
\hline$\omega$ & -0.164 & -0.219 & -0.110 & -0.204 & -0.132 & 0.110 & 0.073 & -0.007 \\
\hline$\alpha$ & 0.077 & 0.062 & 0.091 & 0.067 & 0.087 & 0.029 & 0.020 & -0.000 \\
\hline$\beta$ & 0.754 & 0.687 & 0.821 & 0.709 & 0.793 & 0.134 & 0.084 & -0.006 \\
\hline
\end{tabular}

\begin{tabular}{|c|c|c|c|c|c|c|c|c|}
\hline WPL & Estimates & $\begin{array}{c}\text { CI - } \\
\text { Lower }\end{array}$ & $\begin{array}{c}\text { CI - } \\
\text { Upper }\end{array}$ & $\begin{array}{c}\text { BCI - } \\
\text { Lower }\end{array}$ & $\begin{array}{c}\text { BCI - } \\
\text { Upper }\end{array}$ & $\begin{array}{c}\text { CI } \\
\text { Width }\end{array}$ & $\begin{array}{c}\text { BCI } \\
\text { Width }\end{array}$ & Asymmetry \\
\hline$\omega$ & -0.331 & -0.472 & -0.190 & -0.414 & -0.264 & 0.282 & 0.150 & -0.017 \\
\hline$\alpha$ & 0.095 & 0.074 & 0.117 & 0.082 & 0.109 & 0.043 & 0.027 & 0.001 \\
\hline$\beta$ & 0.546 & 0.379 & 0.714 & 0.453 & 0.632 & 0.334 & 0.179 & -0.007 \\
\hline
\end{tabular}

\begin{tabular}{|c|c|c|c|c|c|c|c|c|}
\hline CML & Estimates & $\begin{array}{c}\text { CI - } \\
\text { Lower }\end{array}$ & $\begin{array}{c}\text { CI - } \\
\text { Upper }\end{array}$ & $\begin{array}{c}\text { BCI - } \\
\text { Lower }\end{array}$ & $\begin{array}{c}\text { BCI - } \\
\text { Upper }\end{array}$ & $\begin{array}{c}\text { CI } \\
\text { Width }\end{array}$ & $\begin{array}{c}\text { BCI } \\
\text { Width }\end{array}$ & Asymmetry \\
\hline$\omega$ & -0.374 & -0.498 & -0.250 & -0.495 & -0.284 & 0.248 & 0.212 & -0.030 \\
\hline$\alpha$ & 0.105 & 0.077 & 0.132 & 0.085 & 0.128 & 0.055 & 0.043 & 0.003 \\
\hline$\beta$ & 0.471 & 0.320 & 0.622 & 0.317 & 0.597 & 0.302 & 0.280 & -0.028 \\
\hline
\end{tabular}

\begin{tabular}{|c|c|c|c|c|c|c|c|c|}
\hline WOW & Estimates & $\begin{array}{c}\text { CI - } \\
\text { Lower }\end{array}$ & $\begin{array}{c}\text { CI - } \\
\text { Upper }\end{array}$ & $\begin{array}{c}\text { BCI - } \\
\text { Lower }\end{array}$ & $\begin{array}{c}\text { BCI - } \\
\text { Upper }\end{array}$ & $\begin{array}{c}\text { CI } \\
\text { Width }\end{array}$ & $\begin{array}{c}\text { BCI } \\
\text { Width }\end{array}$ & Asymmetry \\
\hline$\omega$ & -0.247 & -0.315 & -0.179 & -0.294 & -0.198 & 0.136 & 0.096 & 0.002 \\
\hline$\alpha$ & 0.119 & 0.100 & 0.138 & 0.105 & 0.133 & 0.038 & 0.028 & -0.000 \\
\hline$\beta$ & 0.600 & 0.511 & 0.689 & 0.539 & 0.664 & 0.178 & 0.126 & 0.003 \\
\hline
\end{tabular}

\begin{tabular}{|c|c|c|c|c|c|c|c|c|}
\hline TLS & Estimates & $\begin{array}{c}\text { CI - } \\
\text { Lower }\end{array}$ & $\begin{array}{c}\text { CI - } \\
\text { Upper }\end{array}$ & $\begin{array}{c}\text { BCI - } \\
\text { Lower }\end{array}$ & $\begin{array}{c}\text { BCI - } \\
\text { Upper }\end{array}$ & $\begin{array}{c}\text { CI } \\
\text { Width }\end{array}$ & $\begin{array}{c}\text { BCI } \\
\text { Width }\end{array}$ & Asymmetry \\
\hline$\omega$ & -0.352 & -0.507 & -0.197 & -0.483 & -0.250 & 0.311 & 0.233 & -0.029 \\
\hline$\alpha$ & 0.129 & 0.096 & 0.163 & 0.104 & 0.158 & 0.067 & 0.054 & 0.003 \\
\hline$\beta$ & 0.602 & 0.464 & 0.740 & 0.485 & 0.698 & 0.276 & 0.213 & -0.020 \\
\hline
\end{tabular}

\begin{tabular}{|c|c|c|c|c|c|c|c|c|}
\hline QAN & Estimates & $\begin{array}{c}\text { CI - } \\
\text { Lower }\end{array}$ & $\begin{array}{c}\text { CI - } \\
\text { Upper }\end{array}$ & $\begin{array}{c}\text { BCI - } \\
\text { Lower }\end{array}$ & $\begin{array}{c}\text { BCI - } \\
\text { Upper }\end{array}$ & $\begin{array}{c}\text { CI } \\
\text { Width }\end{array}$ & $\begin{array}{c}\text { BCI } \\
\text { Width }\end{array}$ & Asymmetry \\
\hline$\omega$ & -0.544 & -0.695 & -0.394 & -0.791 & -0.374 & 0.301 & 0.417 & -0.076 \\
\hline$\alpha$ & 0.111 & 0.079 & 0.142 & 0.083 & 0.137 & 0.063 & 0.054 & -0.002 \\
\hline$\beta$ & 0.335 & 0.181 & 0.489 & 0.112 & 0.531 & 0.308 & 0.419 & -0.027 \\
\hline
\end{tabular}


Table 4b. Confidence Intervals of QMLE with Weibull Density

\begin{tabular}{|c|c|c|c|c|c|c|c|c|}
\hline ANZ & Estimates & $\begin{array}{c}\text { CI - } \\
\text { Lower }\end{array}$ & $\begin{array}{c}\text { CI - } \\
\text { Upper }\end{array}$ & $\begin{array}{l}\text { BCI - } \\
\text { Lower }\end{array}$ & $\begin{array}{l}\text { BCI - } \\
\text { Upper }\end{array}$ & $\begin{array}{c}\text { CI } \\
\text { Width }\end{array}$ & $\begin{array}{c}\text { BCI } \\
\text { Width }\end{array}$ & Asymmetry \\
\hline$\omega$ & -0.627 & -0.759 & -0.495 & -0.244 & -0.145 & 0.264 & 0.099 & 0.864 \\
\hline$\alpha$ & 0.066 & 0.054 & 0.079 & 0.058 & 0.083 & 0.024 & 0.026 & 0.008 \\
\hline$\beta$ & 0.648 & 0.577 & 0.718 & 0.570 & 0.727 & 0.141 & 0.157 & 0.002 \\
\hline $\mathrm{CBA}$ & Estimates & $\begin{array}{c}\text { CI - } \\
\text { Lower }\end{array}$ & $\begin{array}{c}\text { CI - } \\
\text { Upper }\end{array}$ & $\begin{array}{l}\text { BCI - } \\
\text { Lower }\end{array}$ & $\begin{array}{l}\text { BCI - } \\
\text { Upper }\end{array}$ & $\begin{array}{c}\text { CI } \\
\text { Width }\end{array}$ & $\begin{array}{c}\text { BCI } \\
\text { Width }\end{array}$ & Asymmetry \\
\hline$\omega$ & -0.607 & -0.764 & -0.449 & -0.223 & -0.150 & 0.315 & 0.073 & 0.841 \\
\hline$\alpha$ & 0.082 & 0.069 & 0.096 & 0.071 & 0.097 & 0.026 & 0.026 & 0.004 \\
\hline$\beta$ & 0.643 & 0.557 & 0.729 & 0.576 & 0.700 & 0.172 & 0.124 & -0.009 \\
\hline
\end{tabular}

\begin{tabular}{|c|c|c|c|c|c|c|c|c|}
\hline BHP & Estimates & $\begin{array}{c}\text { CI - } \\
\text { Lower }\end{array}$ & $\begin{array}{c}\text { CI - } \\
\text { Upper }\end{array}$ & $\begin{array}{c}\text { BCI - } \\
\text { Lower }\end{array}$ & $\begin{array}{c}\text { BCI - } \\
\text { Upper }\end{array}$ & $\begin{array}{c}\text { CI } \\
\text { Width }\end{array}$ & $\begin{array}{c}\text { BCI } \\
\text { Width }\end{array}$ & Asymmetry \\
\hline$\omega$ & -0.821 & -1.016 & -0.626 & -0.283 & -0.189 & 0.390 & 0.094 & 1.169 \\
\hline$\alpha$ & 0.081 & 0.067 & 0.094 & 0.071 & 0.128 & 0.027 & 0.058 & 0.038 \\
\hline$\beta$ & 0.675 & 0.602 & 0.748 & 0.613 & 0.730 & 0.145 & 0.117 & -0.007 \\
\hline
\end{tabular}

\begin{tabular}{|c|c|c|c|c|c|c|c|c|}
\hline WPL & Estimates & $\begin{array}{c}\text { CI - } \\
\text { Lower }\end{array}$ & $\begin{array}{c}\text { CI - } \\
\text { Upper }\end{array}$ & $\begin{array}{c}\text { BCI - } \\
\text { Lower }\end{array}$ & $\begin{array}{c}\text { BCI - } \\
\text { Upper }\end{array}$ & $\begin{array}{c}\text { CI } \\
\text { Width }\end{array}$ & $\begin{array}{c}\text { BCI } \\
\text { Width }\end{array}$ & Asymmetry \\
\hline$\omega$ & -1.242 & -1.596 & -0.888 & -0.469 & -0.293 & 0.708 & 0.176 & 1.721 \\
\hline$\alpha$ & 0.094 & 0.077 & 0.112 & 0.078 & 0.110 & 0.035 & 0.032 & -0.000 \\
\hline$\beta$ & 0.493 & 0.356 & 0.631 & 0.387 & 0.605 & 0.274 & 0.218 & 0.005 \\
\hline
\end{tabular}

\begin{tabular}{|c|c|c|c|c|c|c|c|c|}
\hline CML & Estimates & $\begin{array}{c}\text { CI - } \\
\text { Lower }\end{array}$ & $\begin{array}{c}\text { CI - } \\
\text { Upper }\end{array}$ & $\begin{array}{c}\text { BCI - } \\
\text { Lower }\end{array}$ & $\begin{array}{c}\text { BCI - } \\
\text { Upper }\end{array}$ & $\begin{array}{c}\text { CI } \\
\text { Width }\end{array}$ & $\begin{array}{c}\text { BCI } \\
\text { Width }\end{array}$ & Asymmetry \\
\hline$\omega$ & -1.342 & -1.706 & -0.978 & -0.596 & -0.255 & 0.728 & 0.342 & 1.833 \\
\hline$\alpha$ & 0.082 & 0.058 & 0.107 & 0.059 & 0.107 & 0.049 & 0.048 & 0.001 \\
\hline$\beta$ & 0.431 & 0.285 & 0.577 & 0.241 & 0.653 & 0.292 & 0.412 & 0.032 \\
\hline
\end{tabular}

\begin{tabular}{|c|c|c|c|c|c|c|c|c|}
\hline WOW & Estimates & $\begin{array}{c}\text { CI - } \\
\text { Lower }\end{array}$ & $\begin{array}{c}\text { CI - } \\
\text { Upper }\end{array}$ & $\begin{array}{c}\text { BCI - } \\
\text { Lower }\end{array}$ & $\begin{array}{c}\text { BCI - } \\
\text { Upper }\end{array}$ & $\begin{array}{c}\text { CI } \\
\text { Width }\end{array}$ & $\begin{array}{c}\text { BCI } \\
\text { Width }\end{array}$ & Asymmetry \\
\hline$\omega$ & -0.935 & -1.140 & -0.731 & -0.322 & -0.223 & 0.409 & 0.100 & 1.326 \\
\hline$\alpha$ & 0.114 & 0.097 & 0.132 & 0.100 & 0.140 & 0.035 & 0.040 & 0.011 \\
\hline$\beta$ & 0.574 & 0.488 & 0.660 & 0.505 & 0.641 & 0.172 & 0.136 & -0.002 \\
\hline
\end{tabular}

\begin{tabular}{|c|c|c|c|c|c|c|c|c|}
\hline TLS & Estimates & $\begin{array}{c}\text { CI - } \\
\text { Lower }\end{array}$ & $\begin{array}{c}\text { CI - } \\
\text { Upper }\end{array}$ & $\begin{array}{c}\text { BCI - } \\
\text { Lower }\end{array}$ & $\begin{array}{c}\text { BCI - } \\
\text { Upper }\end{array}$ & $\begin{array}{c}\text { CI } \\
\text { Width }\end{array}$ & $\begin{array}{c}\text { BCI } \\
\text { Width }\end{array}$ & Asymmetry \\
\hline$\omega$ & -1.569 & -1.949 & -1.188 & -0.494 & -0.296 & 0.761 & 0.197 & 2.347 \\
\hline$\alpha$ & 0.144 & 0.114 & 0.173 & 0.118 & 0.397 & 0.058 & 0.279 & 0.228 \\
\hline$\beta$ & 0.547 & 0.440 & 0.655 & 0.321 & 0.637 & 0.216 & 0.315 & -0.137 \\
\hline
\end{tabular}

\begin{tabular}{|c|c|c|c|c|c|c|c|c|}
\hline QAN & Estimates & $\begin{array}{c}\text { CI - } \\
\text { Lower }\end{array}$ & $\begin{array}{c}\text { CI - } \\
\text { Upper }\end{array}$ & $\begin{array}{c}\text { BCI - } \\
\text { Lower }\end{array}$ & $\begin{array}{c}\text { BCI - } \\
\text { Upper }\end{array}$ & $\begin{array}{c}\text { CI } \\
\text { Width }\end{array}$ & $\begin{array}{c}\text { BCI } \\
\text { Width }\end{array}$ & Asymmetry \\
\hline$\omega$ & -1.777 & -2.175 & -1.379 & -0.786 & -0.301 & 0.795 & 0.485 & 2.468 \\
\hline$\alpha$ & 0.090 & 0.062 & 0.118 & 0.061 & 0.132 & 0.056 & 0.071 & 0.013 \\
\hline$\beta$ & 0.340 & 0.203 & 0.477 & 0.093 & 0.628 & 0.274 & 0.536 & 0.041 \\
\hline
\end{tabular}


Table 4c. Confidence Intervals of QMLE with Exponential Density

\begin{tabular}{|c|c|c|c|c|c|c|c|c|}
\hline ANZ & Estimates & $\begin{array}{c}\text { CI - } \\
\text { Lower }\end{array}$ & $\begin{array}{c}\text { CI - } \\
\text { Upper }\end{array}$ & $\begin{array}{l}\text { BCI - } \\
\text { Lower }\end{array}$ & $\begin{array}{l}\text { BCI - } \\
\text { Upper }\end{array}$ & $\begin{array}{c}\text { CI } \\
\text { Width }\end{array}$ & $\begin{array}{c}\text { BCI } \\
\text { Width }\end{array}$ & Asymmetry \\
\hline$\omega$ & 0.265 & -0.370 & 0.900 & -0.337 & -0.172 & 1.271 & 0.165 & -1.039 \\
\hline$\alpha$ & 0.049 & 0.036 & 0.063 & 0.037 & 0.062 & 0.027 & 0.025 & 0.001 \\
\hline$\beta$ & 0.588 & 0.506 & 0.669 & 0.450 & 0.708 & 0.163 & 0.258 & -0.017 \\
\hline $\mathrm{CBA}$ & Estimates & $\begin{array}{c}\text { CI - } \\
\text { Lower }\end{array}$ & $\begin{array}{c}\text { CI - } \\
\text { Upper }\end{array}$ & $\begin{array}{l}\text { BCI - } \\
\text { Lower }\end{array}$ & $\begin{array}{l}\text { BCI - } \\
\text { Upper }\end{array}$ & $\begin{array}{c}\text { CI } \\
\text { Width }\end{array}$ & $\begin{array}{c}\text { BCI } \\
\text { Width }\end{array}$ & Asymmetry \\
\hline$\omega$ & 0.710 & -0.555 & 1.974 & -0.312 & -0.189 & 2.529 & 0.123 & -1.921 \\
\hline$\alpha$ & 0.068 & 0.057 & 0.079 & 0.058 & 0.079 & 0.022 & 0.021 & 0.001 \\
\hline$\beta$ & 0.578 & 0.425 & 0.730 & 0.466 & 0.659 & 0.305 & 0.194 & -0.031 \\
\hline
\end{tabular}

\begin{tabular}{|c|c|c|c|c|c|c|c|c|}
\hline BHP & Estimates & $\begin{array}{c}\text { CI - } \\
\text { Lower }\end{array}$ & $\begin{array}{c}\text { CI - } \\
\text { Upper }\end{array}$ & $\begin{array}{c}\text { BCI - } \\
\text { Lower }\end{array}$ & $\begin{array}{c}\text { BCI - } \\
\text { Upper }\end{array}$ & $\begin{array}{c}\text { CI } \\
\text { Width }\end{array}$ & $\begin{array}{c}\text { BCI } \\
\text { Width }\end{array}$ & Asymmetry \\
\hline$\omega$ & 1.422 & 0.551 & 2.294 & -0.508 & -0.302 & 1.743 & 0.206 & -3.655 \\
\hline$\alpha$ & 0.073 & 0.060 & 0.086 & 0.061 & 0.087 & 0.026 & 0.026 & 0.002 \\
\hline$\beta$ & 0.530 & 0.420 & 0.640 & 0.400 & 0.626 & 0.220 & 0.226 & -0.034 \\
\hline
\end{tabular}

\begin{tabular}{|c|c|c|c|c|c|c|c|c|}
\hline WPL & Estimates & $\begin{array}{c}\text { CI - } \\
\text { Lower }\end{array}$ & $\begin{array}{c}\text { CI - } \\
\text { Upper }\end{array}$ & $\begin{array}{c}\text { BCI - } \\
\text { Lower }\end{array}$ & $\begin{array}{c}\text { BCI - } \\
\text { Upper }\end{array}$ & $\begin{array}{c}\text { CI } \\
\text { Width }\end{array}$ & $\begin{array}{c}\text { BCI } \\
\text { Width }\end{array}$ & Asymmetry \\
\hline$\omega$ & -2.105 & -4.236 & 0.026 & -0.603 & -0.357 & 4.262 & 0.246 & 3.249 \\
\hline$\alpha$ & 0.077 & 0.058 & 0.095 & 0.062 & 0.111 & 0.037 & 0.049 & 0.020 \\
\hline$\beta$ & 0.383 & 0.219 & 0.548 & 0.270 & 0.551 & 0.329 & 0.281 & 0.054 \\
\hline
\end{tabular}

\begin{tabular}{|c|c|c|c|c|c|c|c|c|}
\hline CML & Estimates & $\begin{array}{c}\text { CI - } \\
\text { Lower }\end{array}$ & $\begin{array}{c}\text { CI - } \\
\text { Upper }\end{array}$ & $\begin{array}{c}\text { BCI - } \\
\text { Lower }\end{array}$ & $\begin{array}{c}\text { BCI - } \\
\text { Upper }\end{array}$ & $\begin{array}{c}\text { CI } \\
\text { Width }\end{array}$ & $\begin{array}{c}\text { BCI } \\
\text { Width }\end{array}$ & Asymmetry \\
\hline$\omega$ & 0.361 & -0.308 & 1.031 & -1.038 & -0.198 & 1.340 & 0.839 & -1.959 \\
\hline$\alpha$ & 0.050 & 0.027 & 0.074 & 0.029 & 0.071 & 0.047 & 0.041 & -0.000 \\
\hline$\beta$ & 0.348 & 0.198 & 0.498 & -0.204 & 0.726 & 0.301 & 0.930 & -0.174 \\
\hline
\end{tabular}

\begin{tabular}{|c|c|c|c|c|c|c|c|c|}
\hline WOW & Estimates & $\begin{array}{c}\text { CI - } \\
\text { Lower }\end{array}$ & $\begin{array}{c}\text { CI - } \\
\text { Upper }\end{array}$ & $\begin{array}{c}\text { BCI - } \\
\text { Lower }\end{array}$ & $\begin{array}{c}\text { BCI - } \\
\text { Upper }\end{array}$ & $\begin{array}{c}\text { CI } \\
\text { Width }\end{array}$ & $\begin{array}{c}\text { BCI } \\
\text { Width }\end{array}$ & Asymmetry \\
\hline$\omega$ & -1.115 & -27.188 & 24.958 & -0.473 & -0.306 & 52.1460 & 0.167 & 1.452 \\
\hline$\alpha$ & 0.100 & -2.270 & 2.469 & 0.082 & 0.118 & 4.739 & 0.036 & 0.001 \\
\hline$\beta$ & 0.451 & -15.709 & 16.611 & 0.359 & 0.559 & 32.320 & 0.200 & 0.015 \\
\hline
\end{tabular}

\begin{tabular}{|c|c|c|c|c|c|c|c|c|}
\hline TLS & Estimates & $\begin{array}{c}\text { CI - } \\
\text { Lower }\end{array}$ & $\begin{array}{c}\text { CI - } \\
\text { Upper }\end{array}$ & $\begin{array}{c}\text { BCI - } \\
\text { Lower }\end{array}$ & $\begin{array}{c}\text { BCI - } \\
\text { Upper }\end{array}$ & $\begin{array}{c}\text { CI } \\
\text { Width }\end{array}$ & $\begin{array}{c}\text { BCI } \\
\text { Width }\end{array}$ & Asymmetry \\
\hline$\omega$ & 1.680 & 0.974 & 2.387 & -0.601 & -0.319 & 1.413 & 0.282 & -4.281 \\
\hline$\alpha$ & 0.129 & 0.102 & 0.155 & 0.105 & 0.170 & 0.054 & 0.065 & 0.018 \\
\hline$\beta$ & 0.553 & 0.441 & 0.666 & 0.406 & 0.638 & 0.226 & 0.231 & -0.063 \\
\hline
\end{tabular}

\begin{tabular}{|c|c|c|c|c|c|c|c|c|}
\hline QAN & Estimates & $\begin{array}{c}\text { CI - } \\
\text { Lower }\end{array}$ & $\begin{array}{c}\text { CI - } \\
\text { Upper }\end{array}$ & $\begin{array}{c}\text { BCI - } \\
\text { Lower }\end{array}$ & $\begin{array}{c}\text { BCI - } \\
\text { Upper }\end{array}$ & $\begin{array}{c}\text { CI } \\
\text { Width }\end{array}$ & $\begin{array}{c}\text { BCI } \\
\text { Width }\end{array}$ & Asymmetry \\
\hline$\omega$ & -0.674 & -1.788 & 0.440 & -1.078 & -0.215 & 2.229 & 0.863 & 0.054 \\
\hline$\alpha$ & 0.057 & 0.033 & 0.080 & 0.023 & 0.094 & 0.047 & 0.071 & 0.004 \\
\hline$\beta$ & 0.368 & 0.205 & 0.530 & -0.153 & 0.738 & 0.325 & 0.892 & -0.150 \\
\hline
\end{tabular}


Table 4d. Confidence Intervals of QMLE with Normal Density

\begin{tabular}{|c|c|c|c|c|c|c|c|c|}
\hline ANZ & Estimates & $\begin{array}{c}\text { CI - } \\
\text { Lower }\end{array}$ & $\begin{array}{c}\text { CI - } \\
\text { Upper }\end{array}$ & $\begin{array}{l}\text { BCI - } \\
\text { Lower }\end{array}$ & $\begin{array}{l}\text { BCI - } \\
\text { Upper }\end{array}$ & $\begin{array}{c}\text { CI } \\
\text { Width }\end{array}$ & $\begin{array}{c}\text { BCI } \\
\text { Width }\end{array}$ & Asymmetry \\
\hline$\omega$ & -0.156 & -0.194 & -0.119 & -0.192 & -0.125 & 0.075 & 0.067 & -0.004 \\
\hline$\alpha$ & 0.080 & 0.067 & 0.093 & 0.070 & 0.092 & 0.026 & 0.022 & 0.003 \\
\hline$\beta$ & 0.695 & 0.633 & 0.756 & 0.638 & 0.745 & 0.122 & 0.107 & -0.005 \\
\hline $\mathrm{CBA}$ & Estimates & $\begin{array}{c}\text { CI - } \\
\text { Lower }\end{array}$ & $\begin{array}{c}\text { CI - } \\
\text { Upper }\end{array}$ & $\begin{array}{l}\text { BCI - } \\
\text { Lower }\end{array}$ & $\begin{array}{l}\text { BCI - } \\
\text { Upper }\end{array}$ & $\begin{array}{c}\text { CI } \\
\text { Width }\end{array}$ & $\begin{array}{c}\text { BCI } \\
\text { Width }\end{array}$ & Asymmetry \\
\hline$\omega$ & -0.161 & -0.208 & -0.113 & -0.190 & -0.129 & 0.094 & 0.061 & 0.003 \\
\hline$\alpha$ & 0.091 & 0.076 & 0.106 & 0.080 & 0.104 & 0.030 & 0.024 & 0.002 \\
\hline$\beta$ & 0.671 & 0.592 & 0.750 & 0.624 & 0.727 & 0.158 & 0.103 & 0.010 \\
\hline
\end{tabular}

\begin{tabular}{|c|c|c|c|c|c|c|c|c|}
\hline BHP & Estimates & $\begin{array}{c}\text { CI - } \\
\text { Lower }\end{array}$ & $\begin{array}{c}\text { CI - } \\
\text { Upper }\end{array}$ & $\begin{array}{c}\text { BCI - } \\
\text { Lower }\end{array}$ & $\begin{array}{c}\text { BCI - } \\
\text { Upper }\end{array}$ & $\begin{array}{c}\text { CI } \\
\text { Width }\end{array}$ & $\begin{array}{c}\text { BCI } \\
\text { Width }\end{array}$ & Asymmetry \\
\hline$\omega$ & -0.164 & -0.216 & -0.113 & -0.203 & -0.130 & 0.103 & 0.073 & -0.004 \\
\hline$\alpha$ & 0.077 & 0.062 & 0.091 & 0.065 & 0.088 & 0.029 & 0.022 & -0.000 \\
\hline$\beta$ & 0.754 & 0.691 & 0.818 & 0.710 & 0.797 & 0.128 & 0.087 & -0.002 \\
\hline
\end{tabular}

\begin{tabular}{|c|c|c|c|c|c|c|c|c|}
\hline WPL & Estimates & $\begin{array}{c}\text { CI - } \\
\text { Lower }\end{array}$ & $\begin{array}{c}\text { CI - } \\
\text { Upper }\end{array}$ & $\begin{array}{c}\text { BCI - } \\
\text { Lower }\end{array}$ & $\begin{array}{c}\text { BCI - } \\
\text { Upper }\end{array}$ & $\begin{array}{c}\text { CI } \\
\text { Width }\end{array}$ & $\begin{array}{c}\text { BCI } \\
\text { Width }\end{array}$ & Asymmetry \\
\hline$\omega$ & -0.331 & -0.471 & -0.190 & -0.404 & -0.256 & 0.281 & 0.148 & 0.002 \\
\hline$\alpha$ & 0.095 & 0.074 & 0.116 & 0.081 & 0.111 & 0.042 & 0.030 & 0.002 \\
\hline$\beta$ & 0.546 & 0.380 & 0.712 & 0.459 & 0.633 & 0.332 & 0.174 & -0.000 \\
\hline
\end{tabular}

\begin{tabular}{|c|c|c|c|c|c|c|c|c|}
\hline CML & Estimates & $\begin{array}{c}\text { CI - } \\
\text { Lower }\end{array}$ & $\begin{array}{c}\text { CI - } \\
\text { Upper }\end{array}$ & $\begin{array}{c}\text { BCI - } \\
\text { Lower }\end{array}$ & $\begin{array}{c}\text { BCI - } \\
\text { Upper }\end{array}$ & $\begin{array}{c}\text { CI } \\
\text { Width }\end{array}$ & $\begin{array}{c}\text { BCI } \\
\text { Width }\end{array}$ & Asymmetry \\
\hline$\omega$ & -0.374 & -0.500 & -0.249 & -0.495 & -0.273 & 0.251 & 0.221 & -0.019 \\
\hline$\alpha$ & 0.105 & 0.077 & 0.132 & 0.085 & 0.127 & 0.055 & 0.043 & 0.003 \\
\hline$\beta$ & 0.471 & 0.321 & 0.622 & 0.326 & 0.593 & 0.301 & 0.267 & -0.024 \\
\hline
\end{tabular}

\begin{tabular}{|c|c|c|c|c|c|c|c|c|}
\hline WOW & Estimates & $\begin{array}{c}\text { CI - } \\
\text { Lower }\end{array}$ & $\begin{array}{c}\text { CI - } \\
\text { Upper }\end{array}$ & $\begin{array}{c}\text { BCI - } \\
\text { Lower }\end{array}$ & $\begin{array}{c}\text { BCI - } \\
\text { Upper }\end{array}$ & $\begin{array}{c}\text { CI } \\
\text { Width }\end{array}$ & $\begin{array}{c}\text { BCI } \\
\text { Width }\end{array}$ & Asymmetry \\
\hline$\omega$ & -0.247 & -0.314 & -0.179 & -0.295 & -0.201 & 0.135 & 0.095 & -0.003 \\
\hline$\alpha$ & 0.119 & 0.101 & 0.138 & 0.106 & 0.133 & 0.037 & 0.027 & -0.000 \\
\hline$\beta$ & 0.600 & 0.512 & 0.688 & 0.541 & 0.661 & 0.175 & 0.120 & 0.002 \\
\hline
\end{tabular}

\begin{tabular}{|c|c|c|c|c|c|c|c|c|}
\hline TLS & Estimates & $\begin{array}{c}\text { CI - } \\
\text { Lower }\end{array}$ & $\begin{array}{c}\text { CI - } \\
\text { Upper }\end{array}$ & $\begin{array}{c}\text { BCI - } \\
\text { Lower }\end{array}$ & $\begin{array}{c}\text { BCI - } \\
\text { Upper }\end{array}$ & $\begin{array}{c}\text { CI } \\
\text { Width }\end{array}$ & $\begin{array}{c}\text { BCI } \\
\text { Width }\end{array}$ & Asymmetry \\
\hline$\omega$ & -0.352 & -0.507 & -0.197 & -0.488 & -0.236 & 0.310 & 0.252 & -0.020 \\
\hline$\alpha$ & 0.129 & 0.095 & 0.164 & 0.100 & 0.157 & 0.068 & 0.057 & -0.002 \\
\hline$\beta$ & 0.602 & 0.463 & 0.741 & 0.497 & 0.700 & 0.278 & 0.203 & -0.007 \\
\hline
\end{tabular}

\begin{tabular}{|c|c|c|c|c|c|c|c|c|}
\hline QAN & Estimates & $\begin{array}{c}\text { CI - } \\
\text { Lower }\end{array}$ & $\begin{array}{c}\text { CI - } \\
\text { Upper }\end{array}$ & $\begin{array}{c}\text { BCI - } \\
\text { Lower }\end{array}$ & $\begin{array}{c}\text { BCI - } \\
\text { Upper }\end{array}$ & $\begin{array}{c}\text { CI } \\
\text { Width }\end{array}$ & $\begin{array}{c}\text { BCI } \\
\text { Width }\end{array}$ & Asymmetry \\
\hline$\omega$ & -0.544 & -0.702 & -0.387 & -0.784 & -0.318 & 0.316 & 0.466 & -0.013 \\
\hline$\alpha$ & 0.111 & 0.077 & 0.144 & 0.082 & 0.137 & 0.067 & 0.055 & -0.002 \\
\hline$\beta$ & 0.335 & 0.173 & 0.496 & 0.081 & 0.561 & 0.323 & 0.479 & -0.027 \\
\hline
\end{tabular}




\section{References}

Barclay, M.J. and J.B Warner (1993), Stealth trading and volatility: which trades move prices?, Journal of Financial Economics, 34, 281-306.

Bauwens, L. and P. Giot (2000), The logarithmic ACD model: an application to the bid-ask quote process of three NYSE stocks, Annales D'Economie et de Statistique, 60, 117-145.

Bauwens, L., F. Galli and P. Giot (2003), The moments of log-ACD models, CORE Discussion Paper. Available at SSRN: http://ssrn.com/abstract=375180 or DOI: $10.2139 /$ ssrn.375180

Bauwens, L. and N. Hautsch, (2006) Modelling financial high frequency data using point processes (CORE DP 2006/80), to appear in Handbook of Financial Time Series, SpringerVerlag.

Bollerslev, T. (1986), Generalized autoregressive conditional heteroscedasticity, Journal of Econometrics, 31, 307-327.

Bollerslev, T. and J.M. Wooldridge (1992), Quasi-maximum likelihood estimation and inference in dynamic models with time-varying covariances, Econometric Reviews, 11, 143-172.

Blume, L., D. Easley, and M. O’Hara (1994), Market statistics and technical analysis: the role of volume, Journal of Finance, 49, 153-181.

Chan, K.S. and H. Tong, (1986), On estimating thresholds in autoregressive models, Journal of Time Series Analysis, 7, 179-190

Chan, L.K.C. and J. Lakonishok (1993), Institutional trades and intraday stock price behavior, Journal of Financial Economics, 33, 173-199.

Engle, R.F. (2000), The econometrics of ultra-high-frequency data, Econometrica, 68, 1-22.

Engle, R.F. and J.R. Russell (1994), Forecasting transaction rates: the autoregressive conditional duration model, National Bureau of Economic Research Working Paper, No 4966.

Engle, R.F. and J.R. Russell (1997), Forecasting the frequency of changes in quoted foreign exchange prices with the autoregressive conditional duration model, Journal of Empirical Finance, 4, 187-212.

Engle, R.F. and J.R. Russell (1998), Autoregressive conditional duration: a new model for irregularly spaced transactions data, Econometrica, 66, 1127-1162.

Dufour, A. and R.F. Engle (2000), Time and the price impact of a trade, Journal of Finance, 55, 2467-2498.

Fernandes, M. and J. Grammig (2006), A family of autoregressive conditional duration models, Journal of Econometrics, 130, 1-23.

Feng, D., G.J. Jiang, and P.X.K. Song (2004), Stochastic conditional duration models with "leverage effect" for financial transaction data, Journal of Financial Econometrics, 2, 390-421. 
Glosten, L.R., R. Jagannathan and D.E. Runkle (1992), On the relation between the expected value and volatility of the nominal excess return on stocks, Journal of Finance, 46, 1779-1801.

Ghysels, E. and J. Jasiak (1997), GARCH for irregularly spaced financial data: the ACD GARCH model, Working Paper, Department of Economics, Pennsylvania State University.

Hautsch, N. (2006), Testing the conditional mean function of autoregressive conditional duration models, Working Paper, Department of Economics, University of Copenhagen.

Hansen, B.E. (1994), Autoregressive conditional density estimation, International Economic Review, 35, 705-30

Hujer, R., S. Kokot and S. Vuletic (2003), Comparison of MSACD models, Working Paper, Faculty of Economics and Business Administration, Johann Wolfgang Goethe-University.

Karpoff, J.M. (1988), Costly short sales and the correlation of returns with volume, Journal of Financial Research, 11, 173-188.

Kyle, A. (1985), Continuous auctions and insider trading, Econometrica, 53, 1315-1335.

Lee, S.-W. and B.E. Hansen (1994), Asymptotic theory for the GARCH(1,1) quasi-maximum likelihood estimator, Econometric Theory, 10, 29-52.

Ling, S. and M. McAleer (2003), Asymptotic theory for a vector ARMA-GARCH model, Econometric Theory, 19, 278-308.

McAleer, M. (2005), Automated inference and learning in modelling financial volatility, Econometric Theory, 21, 232-261.

Madhavan, A. and S. Smidt (1991), A Bayesian model of intraday specialist pricing, Journal of Financial Economics, 30, 99-134.

Meitz, M. and T. Terasvirta (2006), Evaluating models of autoregressive conditional duration, Journal of Business \& Economic Statistics, 24, 104-124.

Nelson, D.B. (1991), Conditional heteroscedasticity in asset returns: a new approach, Econometrica, 59, 347-370.

Russell, J.R. and R.F. Engle (2005), A discrete-state continuous-time model of financial transactions prices and times: the autoregressive conditional multinomial autoregressive conditional duration model, Journal of Business and Economic Statistics, 23, 166-180.

Stout, W. (1974), Almost Sure Convergence, New York, Academic Press.

Tong, H. (1983), Threshold Models in Non-linear Time Series Analysis, Lecture Notes in Statistics, Volume 21, Springer-Verlag.

Zhang, M.Y., J.R. Russell and R.S. Tsay (2001), A non-linear autoregressive conditional duration model with applications to financial transaction data, Journal of Econometrics, 104, 179-207. 